\title{
Optimization of Hydroacoustic Deployments at John Day Dam
}

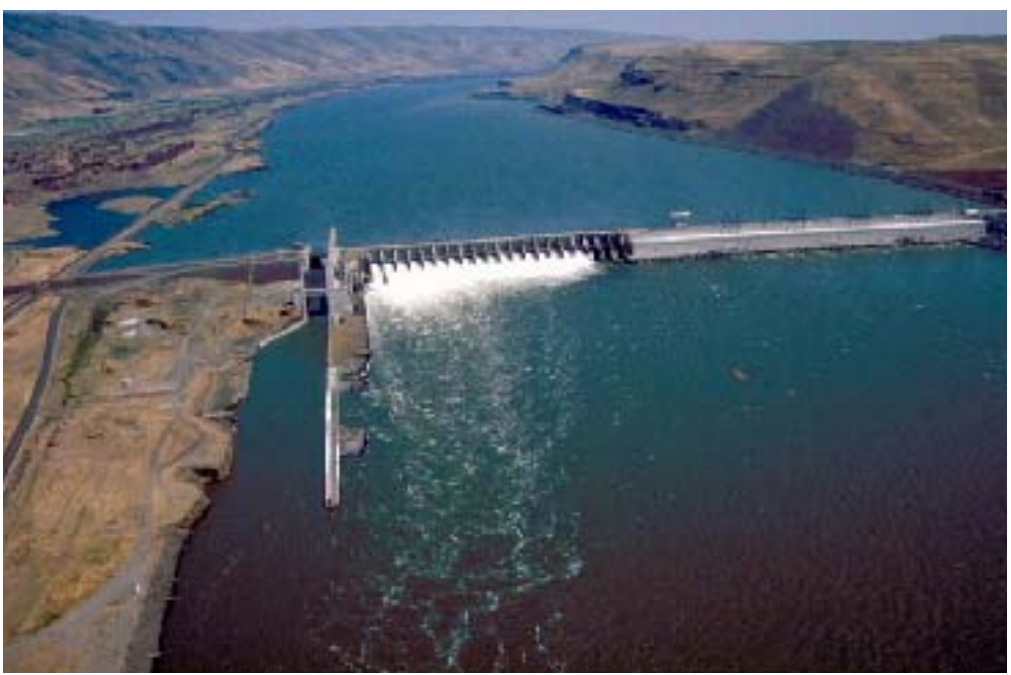

G.R. Ploskey

C.B Cook

P.S. Titzler

R.A. Moursund

November 2002

Prepared for the

U.S. Army Corps of Engineers

Under a Related Services Agreement

With the U.S. Department of Energy

Contract DE-AC0676RLO1830

\section{Pacific Northwest National Laboratory}

Operated by Battelle for the U.S. Department of Energy 


\title{
DISCLAIMER
}

This report was prepared as an account of work sponsored by an agency of the United States Government. Neither the United States Government nor any agency thereof, nor Battelle Memorial Institute, nor any of their employees, makes any warranty, express or implied, or assumes any legal liability or responsibility for the accuracy, completeness, or usefulness of any information, apparatus, product, or process disclosed, or represents that its use would not infringe privately owned rights. Reference herein to any specific commercial product, process, or service by trade name, trademark, manufacturer, or otherwise does not necessarily constitute or imply its endorsement, recommendation, or favoring by the United States Government or any agency thereof, or Battelle Memorial Institute. The views and opinions of authors expressed herein do not necessarily state or reflect those of the United States Government or any agency thereof.

\author{
PACIFIC NORTHWEST NATIONAL LABORATORY \\ operated by \\ BATTELLE \\ for the
}

UNITED STATES DEPARTMENT OF ENERGY

under Contract DE-AC06-76RL01830

Printed in the United States of America

\author{
Available to DOE and DOE contractors from the \\ Office of Scientific and Technical Information, \\ P.O. Box 62, Oak Ridge, TN 37831-0062; \\ ph: (865) 576-8401 \\ fax: (865) 576-5728 \\ email: reports@adonis.osti.gov
}

Available to the public from the National Technical Information Service, U.S. Department of Commerce, 5285 Port Royal Rd., Springfield, VA 22161

ph: (800) 553-6847

fax: (703) 605-6900

email: orders@ntis.fedworld.gov

online ordering: http://www.ntis.gov/ordering.htm 


\title{
Optimization of Hydroacoustic Deployments at John Day Dam
}

\author{
G.R. Ploskey \\ C.B. Cook \\ P.S. Titzler \\ R.A. Moursund
}

November 2002

Prepared for

the U.S. Army Corps of Engineers

Portland District, Portland, Oregon

under Contract DE-AC0676RLO1830

Pacific Northwest National Laboratory

P.O. Box 999

Richland, Washington 99352 



\section{Summary}

This report describes results of short-term studies conducted in late November and early December 2001 to optimize hydroacoustic sampling techniques at John Day Dam before the 2002 fish passage efficiency (FPE) study for the U.S. Army Corps of Engineers. The purpose of the field study was to test deployment locations and aiming angles for optimizing hydroacoustic sampling at John Day Dam. In addition, a computational fluid dynamics model was applied to a single John Day Spillbay to help assess the detectability of smolt-sized fish with hydroacoustic equipment.

Knowledge gained in this study should significantly improve hydroacoustic sampling and the accuracy of ${ }^{\circ}$ estimates of fish passage at two locations that have presented problems in past studies. The spillway has been the most problematic because many fish detected there were not entrained. Without correction, non-commitment of fish can result in multiple detections and overestimation of fish passage and fish passage efficiency. Trash-rack-mounted, down-looking transducers for sampling unguided fish at a submerged traveling screen (STS) also have posed problems because the beam was aimed so far downstream that researchers had concerns about fish aspect and detectability. The deployments, aiming angles, and ping rates described here should eliminate most sampling problems encountered in previous studies.

The spill-bay deployments identified in this study should minimize multiple detections of fish by limiting the sample volume for counting fish to the deep high-discharge volume adjacent to the gate. We recommend mounting each 10-degree spillway transducer on the bottom of a 21 -ft-long, 3.5-inchdiameter pipe and aiming the transducer $2^{\circ}$ downstream from vertical. This aiming angle will place the beam as close as possible to the tainter gate. Angles $<2$ degrees downstream of vertical run the risk of missing fish diving along the gate downstream of the transducer. Beams aimed upstream of vertical run the risk of detecting uncommitted fish. Other recommendations include a pulse repetition rate of $\geq 25$ pings/s and a minimum range for counting fish that depends upon the gate opening. Sample volumes from the minimum range to the range of echoes from the ogee are truncated cones that should be adequate to detect fish diving near the gate from above or moving horizontally over the ogee. Sample volumes are confined to a high flow zone so that fish detected at shorter ranges higher in the water column are excluded. The CFD modeling effort was a critical part of determining preliminary ranges for counting fish at the spillway. From CFD velocity plots as a function of gate opening, we selected minimum ranges that would exclude fish in flows less than about $6 \mathrm{ft} / \mathrm{s}$ at any gate opening. The proposed minimum transducer ranges for counting fish are $38 \mathrm{ft}$ for gates opened $\geq 3 \mathrm{ft}, 43 \mathrm{ft}$ for gates opened $2 \mathrm{ft}$, and $46 \mathrm{ft}$ for gates opened $1 \mathrm{ft}$. The exact minimum range can be fine-tuned as data are collected in 2002 without risk to the study because range filters are applied in post-processing after all data have been acquired.

At Intake 8 $\underline{\mathrm{c}}$ with a STS, a diver mounted two transducers on separate rotators on a horizontal cross member of the deepest trash rack section; we were able to aim one transducer upstream of the screen tip and the other downstream of the screen while still detecting the tip of the screen on the edge of each beam. This was a particularly good deployment because both transducers had similar echo-trace characteristics and detectability. More importantly, the upstream beam can be used to count both guided and unguided fish simultaneously by defining a minimum range for counting guided fish and a maximum 
range for counting unguided fish. If the unguided estimate can be made to correlate well with counts of unguided fish in the downstream transducer beam, then sampling with one beam has distinct advantages. By slow-multiplexing one transducer and simultaneously sampling both guided and unguided fish, researchers could double the ping rate over what is required to fast multiplex two transducers. This would increase the average number of echoes per fish and could improve both detectability and the certainty of detecting traces from fish and not from noise events. Simultaneous sampling of guided and unguided components with one or two beams is desirable because the covariance of passage estimates can be used to reduce the overall variance in FGE estimates. We were able to fast multiplex two transducers at 30 pings/s (15 pings/s for each transducer) with no degradation in signal to noise ratios, so we expect that a pulse repetition rate of 25 to $30 \mathrm{pings} / \mathrm{s}$ should be possible for a slow multiplex of two transducers or for sampling a single transducer.

The optimum aiming angles for the in-turbine deployment were $42^{\circ}$ and $58^{\circ}$ off of the trash-rack plane for the beams aimed upstream and downstream of the screen tip, sampling guided and unguided fish respectively. Variations in STS deployments, transducer mounts, mounting locations, and mounting surfaces among intakes likely account for differences between the aiming angles determined in this study and those that proved acceptable in the 2002 FPE study. Achievable aiming angles in the 2002 FPE study ranged from $33^{\circ}$ to $42^{\circ}$ and from $58^{\circ}$ to $64^{\circ}$. The $42^{\circ}$ and $58^{\circ}$ angles placed transducer beams as close as possible to the STS but provided no leeway for error, which is needed when divers are installing and must manually re-aim many transducers. For future FPE studies, we recommend initially installing transducers with more conservative aiming angles such as $36^{\circ}$ and $63^{\circ}$ off of the trash rack plane so that few transducers will need to be re-aimed.

Divers' deployments of new streamlined transducer mounts through the vertical trash-rack bars and of PVC pipe conduit for routing transducer cables through the trash-rack drain holes were both successful. With these innovations, penetration dives can be avoided at most units in the future, reducing costs and risks to divers.

A two-dimensional computational fluid dynamics model was applied to a generic John Day Spillbay. This model assumed that lateral variations were negligible. To check the sensitivity of the CFD model to input assumptions, numerical results were re-simulated using various turbulence closures and grid resolution. Simulation results from these sensitivity tests produced results upstream of the tainter gate that were virtually identical.

CFD results were validated against 1:25 scale physical model measurements from Northwest Hydraulic Consultants. Observations made in the physical model compared favorably with those simulated by the CFD model. Velocity magnitude results were found to be similar at all locations and matched with a linear regression $\mathrm{R}^{2}$ of 0.98 . The validated CFD model was used to generate velocity fields for gate openings between one and ten feet in one-foot increments. Numerical results throughout the domain have been archived to support potential hydroacoustic studies in the future. 


\section{Contents}

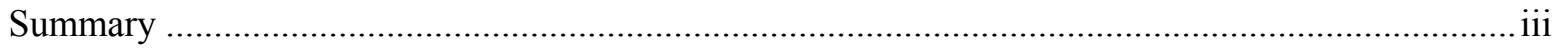

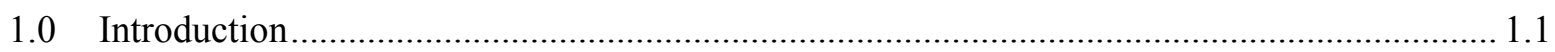

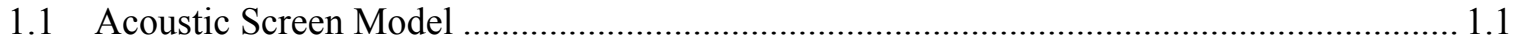

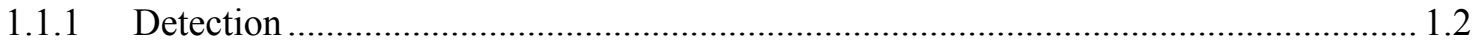

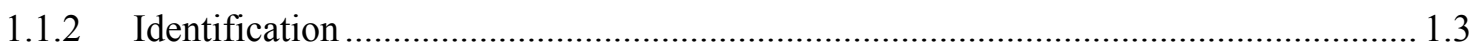

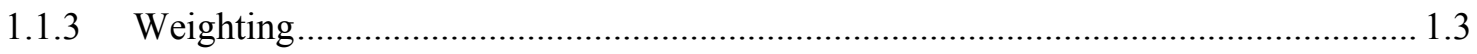

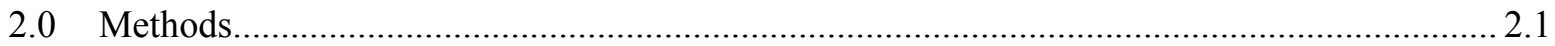

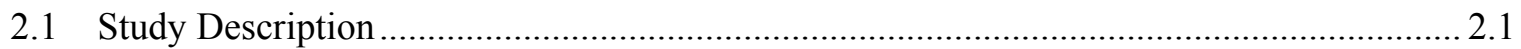

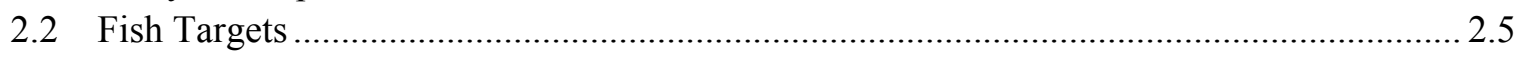

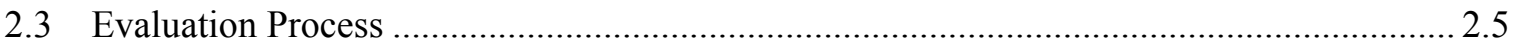

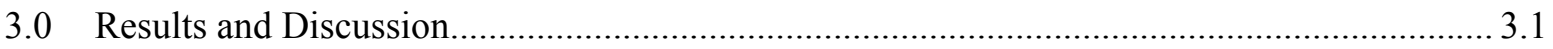

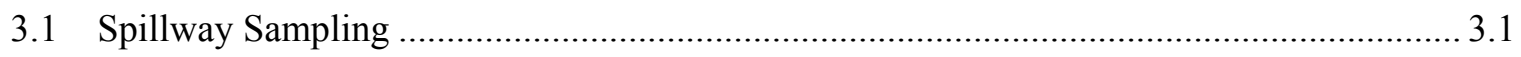

3.2 Sampling Turbines with Submerged Traveling Screens …........................................... 3.7

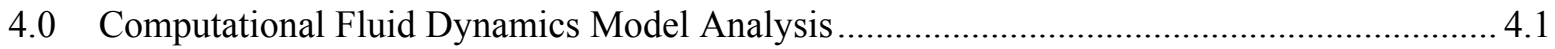

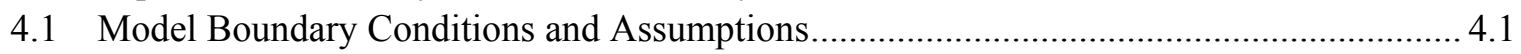

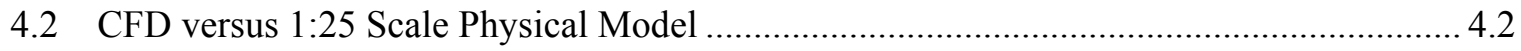

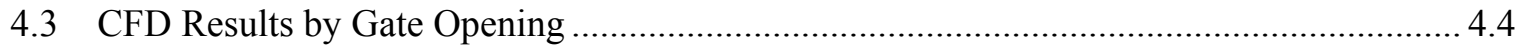

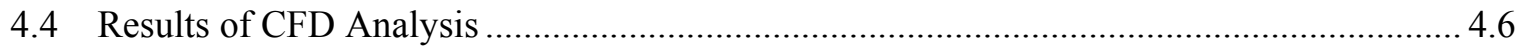

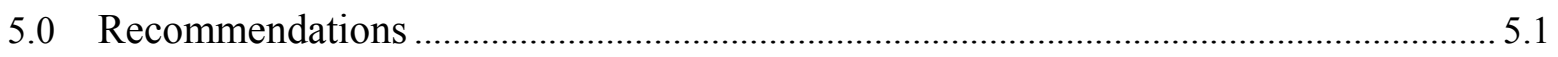

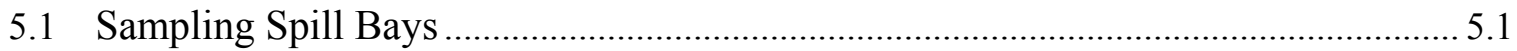

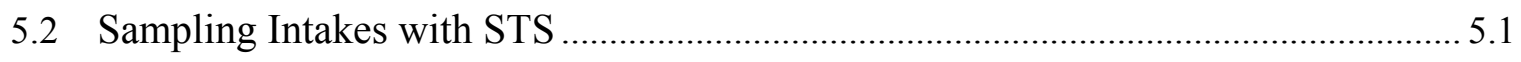

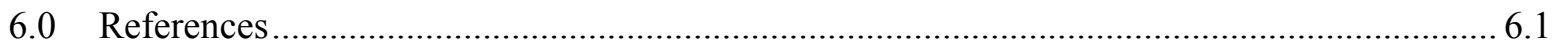


Optimization of Hydroacoustic Deployments at John Day Dam 


\section{Figures}

Figure 1.1. Cross-Sectional Drawing of a John Day Turbine Intake with an ESBS and Transducer Beams for Sampling Guided and Unguided Fish in 1996

Figure 2.1. Hydroacoustic Deployment Evaluated in April 2002 for Estimating the Fish Guidance Efficiency of an Extended Submerged Bar Screen.

Figure 2.2. Hydroacoustic Deployment for Estimating the Fish-Guidance Efficiency of a Submerged Traveling Screen

Figure 2.3. Transducer Deployment for Sampling the Spillway at John Day Dam.

Figure 3.1. Cross-Sectional Drawing of Spill Bay 17 Showing and the Range of Aiming Angles for Hydroacoustic Beams i.e., $19^{\circ}$ Downstream of Vertical to $13^{\circ}$ Upstream and the Optimum Aiming Angle.

Figure 3.2. Echogram Showing a 15-Echo Fish Trace in the Dashed Box at 4 to $5 \mathrm{~m}$ from the Transducer, Which Was Aimed 13 Degrees Upstream of Vertical.

Figure 3.3. Echogram Showing a 45-Echo Trace from a $-45 \mathrm{~dB}$ Fish in the Dashed Box at about $9.5 \mathrm{~m}$ from the Transducer, Which Was Aimed 13 Degrees Upstream of Vertical.

Figure 3.4. Echogram Showing a 10-Echo, $-47 \mathrm{~dB}$ Fish Trace in the Dashed Box at about $11.7 \mathrm{~m}$ from the Transducer, Which Was Aimed 13 Degrees Upstream of Vertical.

Figure 3.5. Echogram Showing a 16-Echo Fish Trace (in the dashed box) at about $14.5 \mathrm{~m}$ from the Transducer, Which Was Aimed $19^{\circ}$ Downstream of Vertical..

Figure 3.6. Echogram Showing Several Echo Traces from Fish at about $9.5 \mathrm{~m}$ with the Transducer Aimed $16^{\circ}$ Downstream of Vertical.

Figure 3.7. Echogram with an Echo Trace from a Fish at about $14 \mathrm{~m}$ and a Band of Noise

Figure 3.8. Cross Sectional View of Intake $8 \underline{\mathrm{c}}$ with a Submerged Traveling Screen Deployed from the Gatewell Slot.

Figure 3.9. Echogram from a Transducer Aimed Directly at the Screen Tip at a Range of about $14.8 \mathrm{~m}$.

Figure 3.10. Echogram from a Transducer Aimed $42^{\circ}$ Downstream from the Trash-Rack Plane Showing Traces of One or Two Guided Fish Passing Above the Tip of the Screen (at $15 \mathrm{~m}$ ) and Below the Intake Ceiling (at $19.6 \mathrm{~m}$ ) 
Figure 3.11. Echogram from a Transducer Aimed $42^{\circ}$ Downstream of the Trash-Rack Plane Showing Steep Traces of Three Unguided Fish Passing Short of the Range of the Screen Tip (at about $15 \mathrm{~m}$ ) on the Upstream Beam for Sampling Guided Fish.

Figure 3.12. Echogram from a Transducer Aimed $42^{\circ}$ Downstream of the Trash-Rack Plane Showing Steep Traces of Two Unguided Fish Passing 6 to $7 \mathrm{~m}$ Short of the Screen Tip

Figure 3.13. Echogram from a Transducer Aimed $58^{\circ}$ Downstream from the Trash-Rack Plane Showing Steep Traces of Two Unguided Fish Passing Short of the Range of the Screen Tip (at about $15 \mathrm{~m}$ ) in the Downstream Beam for Sampling Unguided Fish

Figure 3.14. Side and Front Views of a New Transducer Mount for Trash-Rack Deployments at John Day Dam.

Figure 3.15. Front View of a Turbine Intake at John Day Dam Showing Six Trash Racks and the Deployment of $73.2 \mathrm{ft}$. of PVC Pipe Conduit through Drain Holes

Figure 4.1. CFD versus Physical Model Results.

Figure 4.2. Comparison between CFD and Physical Model Velocities

Figure 4.3. CFD Model Calculated Water Velocity Magnitude Contours of a Single Spillway Bay ... 4.4

\section{Tables}

Table 2.1. Spill Schedule for Testing at Spill Bay 17.

Table 4.1. Discharge Under a Single John Day Spillway Gate at a Forebay Elevation of $263.3 \mathrm{ft}$ 


\subsection{Introduction}

In December 2001 and January 2002, the Pacific Northwest National Laboratory conducted hydroacoustic sampling at John Day Dam for the U.S. Army Corps of Engineers, through the Anadromous Fish Program. The purpose of the field study was to test transducer locations, aiming angles, and pulse-repetition rates for optimizing fish sampling with hydroacoustic equipment at John Day Dam. This report also describes a computational fluid dynamics model of the John Day Spillway constructed to quantitatively understand velocity fields upstream of the tainter gate for fish detectability modeling.

Hydroacoustic sampling is used to estimate the numbers of juvenile salmonids passing the dam in the spillway and turbines. Route-specific passage numbers are important for estimating the survival of juvenile salmonids, for improving the efficacy of juvenile bypass systems, and for optimizing fish passage routes.

In the past, researchers have had difficulty conducting hydroacoustic sampling at John Day Dam's spillway and turbines. Hydroacoustic studies at John Day Dam have not been standardized in terms of deployments or operation of equipment (Poe et al. 2001). Several deployment issues pertaining to the estimation of fish guidance efficiency (FGE) for an extended submerged bar screen (ESBS) have been raised (e.g., Ploskey and Carlson 1999). The 2000 hydroacoustic study data were compromised because previously used deployments for the spillway and submerged traveling screens (STS) proved inadequate. Fish sampled at the spillway were not always entrained when detected, and the trash-rack-mounted, down-looking transducer for sampling unguided fish at a STS was aimed so far downstream that researchers had concerns about fish aspect and detectability. Prior sampling of unguided fish at an ESBS was with a down-looking transducer mounted on the uppermost trash rack (Figure 1.1). Such trash-rack deployments for sampling fish screens require researchers to select an arbitrary minimum range from a transducer beyond which fish are counted. This minimum range is usually the distance from the transducer to a point just above the screen tip. Fish intercepted near the distal end of the screen often pass below the screen and are unguided. Trash-rack deployments have worked well at Bonneville Dam and still must be used to sample guided fish at John Day Dam because there is no alternative.

\subsection{Acoustic Screen Model}

All transducers used in this evaluation were split-beams to provide fish velocity and trajectory data to assess some of the basic assumptions of the acoustic screen model, as described below. Researchers must have uniform detectability among samples and ranges within samples to obtain reliable estimates of routespecific fish passage, fish guidance efficiency (FGE), spill efficiency, and project fish passage efficiency (FPE). The acoustic screen model is used to estimate spatial expansion factors for counts of detected fish.

The assumptions of the acoustic screen model can be classified under three parts of the fish-passage estimation process: detection, identification, and weighting. We only included assumptions pertinent to this study; there are many more in other applications of quantitative hydroacoustics, e.g., marine biomass 


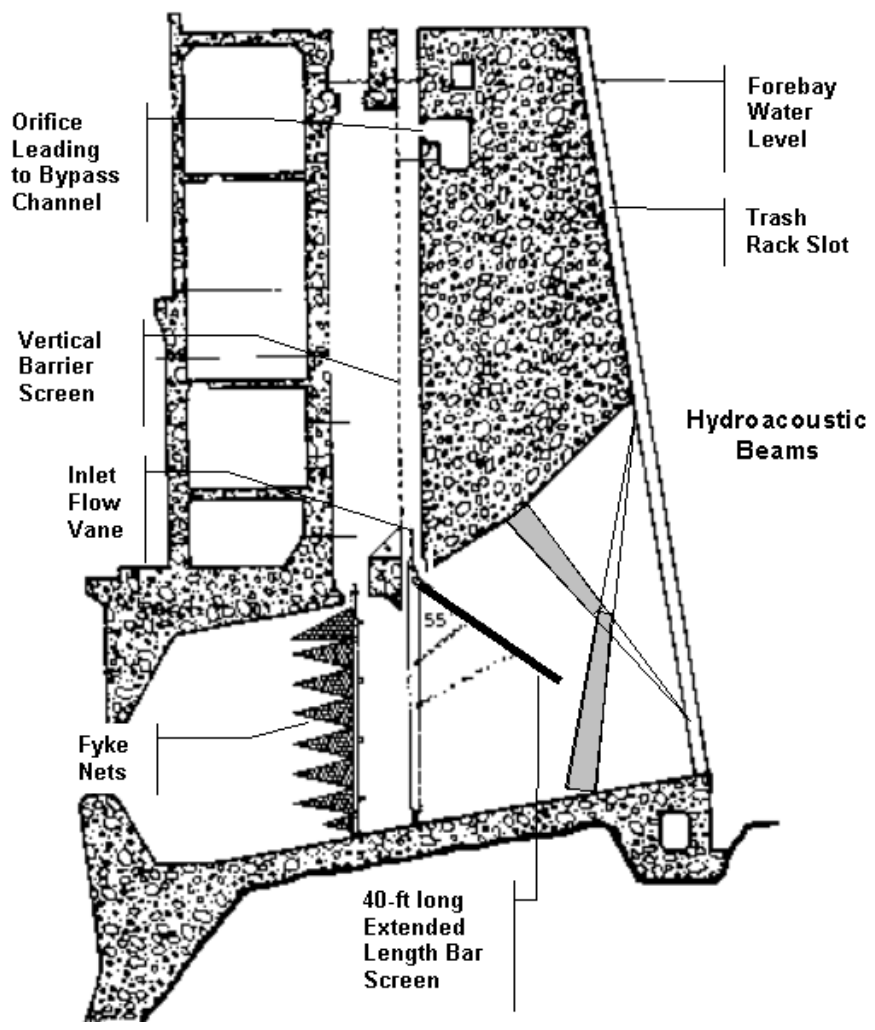

Figure 1.1. Cross-Sectional Drawing of a John Day Turbine Intake with an ESBS and Transducer Beams for Sampling Guided and Unguided Fish in 1996

estimation. The Principle of Equivalency applies to all assumptions when relative passage rate estimates are made. The principle says that the acoustic screen model is valid as long as the elements, such as detectability, are equivalent from location to location.

\subsubsection{Detection}

Detection has to do with the ability of the hydroacoustic system to accurately acquire fish echo data. We assume a scientific quality hydroacoustic system is used, i.e., one that has an accurate and stable timevaried gain, adjustable ping rate and pulse width, and known source level, receiving sensitivity, and beam pattern directivity. The detection assumptions are as follows:

1. The sound energy does not affect fish behavior.

2. All targets of interest within the effective beam angle are detected, i.e., targets of interest are not truncated.

3. Minimum detectability exists such that at least a certain number of echoes (usually four) are recorded for each fish in the beam.

4. Detectability by range from transducer is known or can be modeled.

5. System performance is stable during a study. 


\subsubsection{Identification}

Identification is the process of extracting fish traces from the echo data. This is also called trace formation or pattern recognition. The identification assumptions are as follows:

1. Targets do not overlap, i.e., no masking or multiple targets.

2. There are no false targets.

3. A fish counted at a particular passage route actually passed by that route.

4. The same fish is not identified (counted) more than once, i.e., no multiple counts.

5. The identification process is consistent over transducer locations and time.

\subsubsection{Weighting}

Weighting is the analysis step where individual fish detections (traces) from the acoustic sample are extrapolated to the full width of the passage route being sampled. The weighting assumptions are as follows:

1. Estimates can be made of the effective beam angle ( $\left.\theta_{\text {eff }}\right)$ for each fish at its range of detection.

2. Population target strength (mean) can be estimated for all sample routes.

3. Horizontal distribution across the passage route width ( $\mathrm{P}$ in Figure 1) for a given range from the transducer is uniform. 
Optimization of Hydroacoustic Deployments at John Day Dam 


\subsection{Methods}

\subsection{Study Description}

This study sought to improve sampling at John Day Dam by testing new transducer deployments and aiming angles at a turbine intake with an ESBS, another with a STS, and at one spill bay.

The test deployment at an ESBS was not possible at the time of this study in 2001 because there was no unit available. However, an ESBS deployment was conducted at the beginning of the fish-sampling season, April 2002, and results will be discussed in a future report; a description of the deployment is provided here. The 2002 ESBS deployment consisted of a transducer located on the downstream side of the ESBS below the pivot point and another mounted on the first trash rack (Figure 2.1). Advantages of the ESBS deployment for sampling unguided fish are that there will be no question that fish detected near the screen tip were unguided, and divers will not be required to deploy the transducer. This deployment works better for a $40-\mathrm{ft}$ ESBS than it does for a 20 -ft STS because of the differences in screen length. Near the screen tip, the diameter of a beam aimed down behind an STS would be much narrower than that of a beam aimed down behind an ESBS.

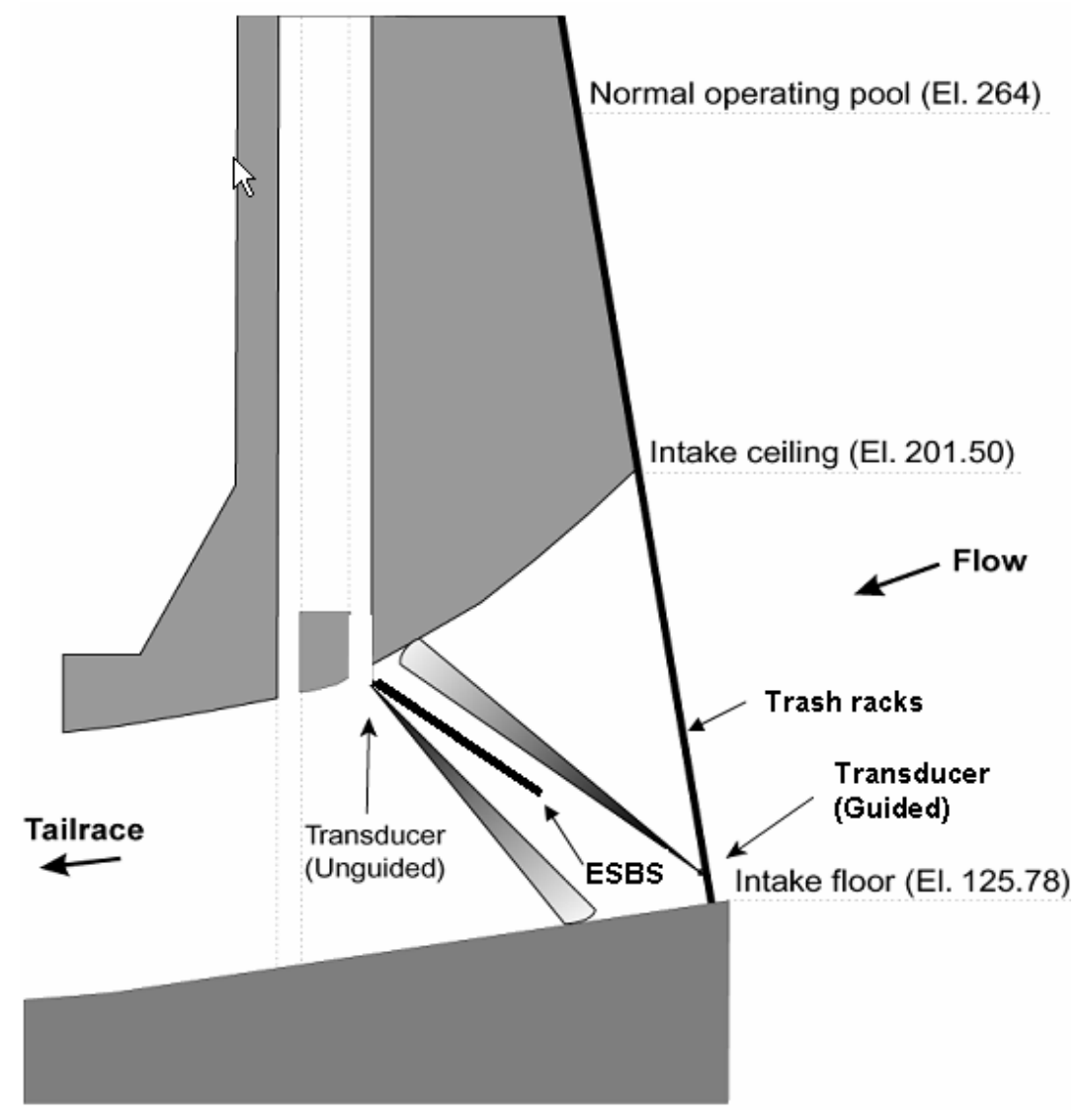

Figure 2.1. Hydroacoustic Deployment Evaluated in April 2002 for Estimating the Fish Guidance Efficiency of an Extended Submerged Bar Screen 
The deployment for sampling guided and unguided fish in an intake with a STS consisted of two uplooking transducers mounted on the bottom trash rack of Intake 8ㅁ (Figure 2.2). Divers mounted a dual transducer mount on a horizontal shelf in the middle of the bottom trash rack. The transducers were on rotators so they could be rotated to optimum aiming angles relative to the trash rack plane. The general orientation of the beam sampling unguided fish was similar to that of the beam for sampling guided fish (Figure 2.2). We fast multiplexed the transducers to determine the maximum possible pulse-repetition rate. The up-looking transducers were attached to single-axis rotators with remote angle display so that the optimum aiming angle could be determined from a topside readout. Transducers were installed on 29 November 2001, and we sampled from about 2100 hours until about 1400 hours the next day. Unfortunately, the turbine was off most of 30 November and no usable data were collected on that day. To acquire more data when the turbine was running, we returned on 7 December at 1500 hours and sampled continuously until 11 December at 0800 hours.

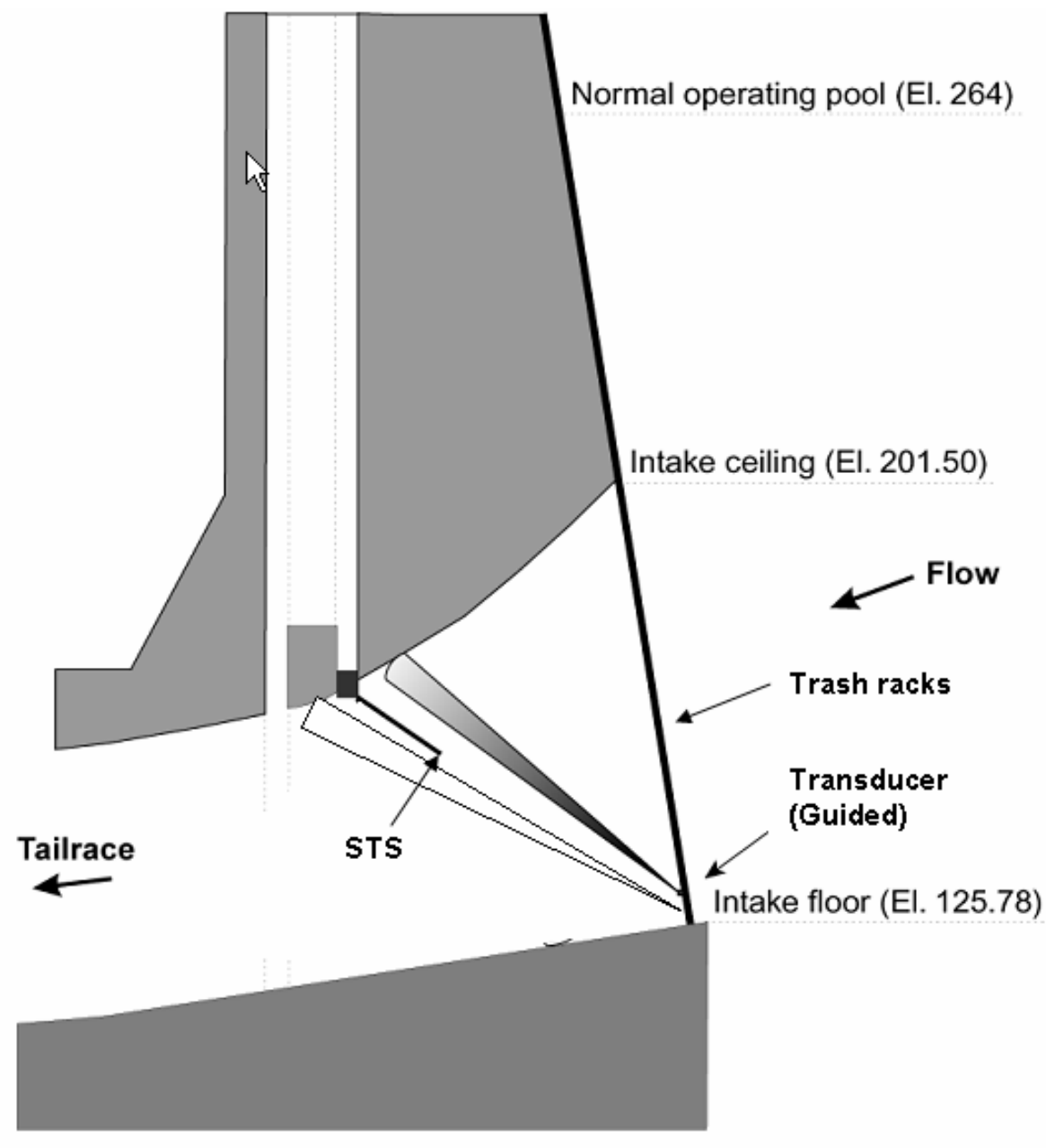

Figure 2.2. Hydroacoustic Deployment for Estimating the Fish-Guidance Efficiency of a Submerged Traveling Screen 
For the spill-bay deployment, we mounted a transducer at the bottom of a 21-ft-long vertical pipe extending from the downstream wall of the stop-log slot below the roadway to about $1 \mathrm{~m}$ below the water's surface at spill bay 17 on 27 November (Figure 2.3). The transducer was on a rotator so we could search for an optimum aiming angle that could be measured after the crane retrieved the mount at the end of sampling. The rotator did not provide feedback on where the transducer was aimed, so we only knew how it was aimed when it went in and after it came out. The objective was to find angles associated with the cleanest echogram and the one aimed closest to the tainter gate. Spillway sampling began on 28 November at about 1400 hours and ended at about 1500 hours on 30 November. During sampling, spill discharge through Bay 17 was varied according to a specific schedule (Table 2.1).

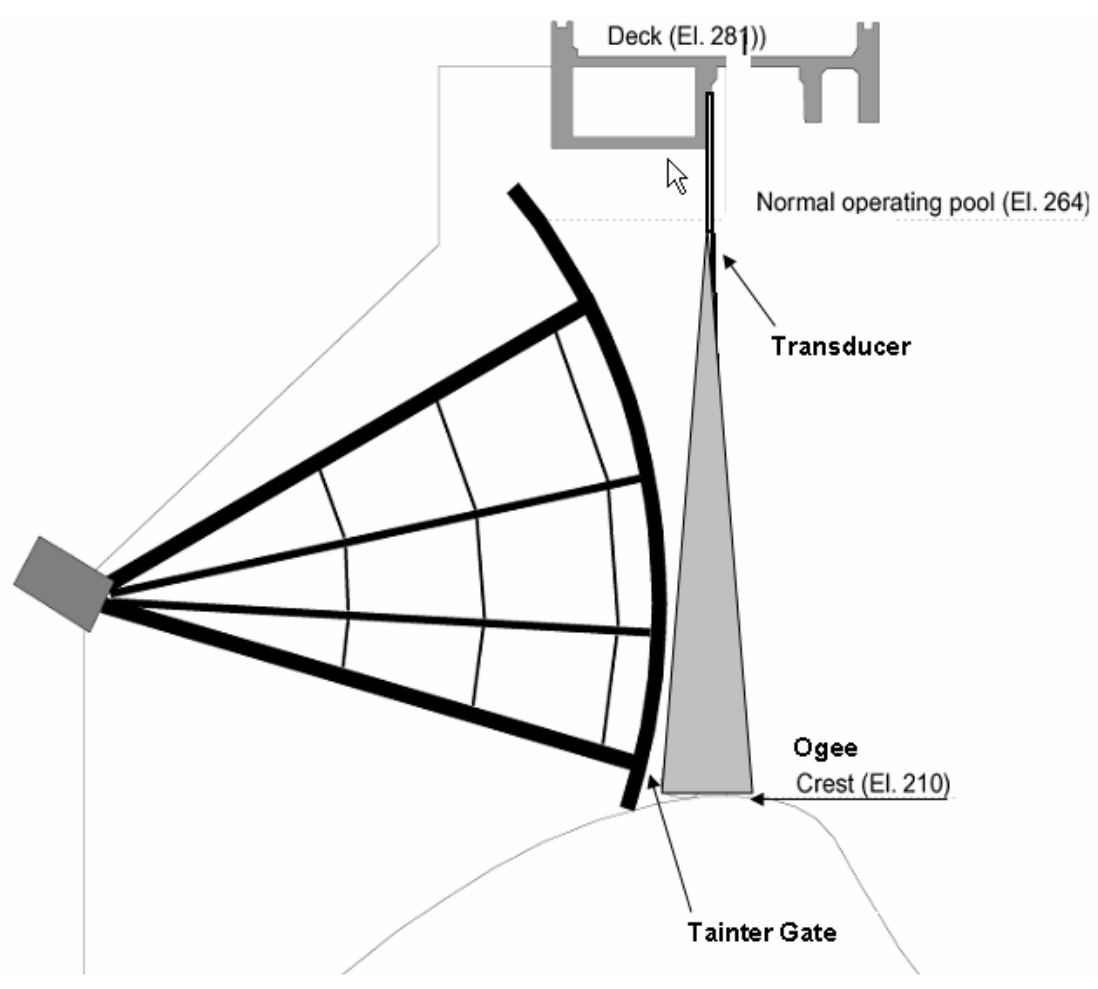

Figure 2.3. Transducer Deployment for Sampling the Spillway at John Day Dam 
Table 2.1. Spill Schedule for Testing at Spill Bay 17

\begin{tabular}{|c|c|c|c|c|}
\hline Date & Hour & Spill Stop (ft) & KCFS & Comment \\
\hline \multirow[t]{10}{*}{$28-\mathrm{Nov}$} & 1400 & 7 & 11.2 & Wednesday \\
\hline & 1500 & 6 & 9.6 & \\
\hline & 1600 & 5 & 8 & \\
\hline & 1700 & 4 & 6.4 & \\
\hline & 1800 & 3 & 4.8 & \\
\hline & 1900 & 2 & 3.2 & \\
\hline & 2000 & 1 & 1.6 & \\
\hline & 2100 & 1 & 1.6 & \\
\hline & 2200 & 1 & 1.6 & \\
\hline & 2300 & 2 & 3.2 & \\
\hline \multirow[t]{25}{*}{ 29-Nov } & 0 & 2 & 3.2 & Thurday \\
\hline & 100 & 2 & 3.2 & \\
\hline & 200 & 1 & 1.6 & \\
\hline & 300 & 1 & 1.6 & \\
\hline & 400 & 1 & 1.6 & \\
\hline & 500 & 2 & 3.2 & \\
\hline & 600 & 2 & 3.2 & \\
\hline & 700 & 2 & 3.2 & \\
\hline & 800 & 1 & 1.6 & \\
\hline & 900 & 1 & 1.6 & \\
\hline & 1000 & 1 & 1.6 & \\
\hline & 1100 & 3 & 4.8 & \\
\hline & 1200 & 3 & 4.8 & \\
\hline & 1300 & 3 & 4.8 & \\
\hline & 1400 & 1 & 1.6 & \\
\hline & 1500 & 1 & $\overline{1.6}$ & \\
\hline & 1600 & 1 & 1.6 & \\
\hline & 1700 & 2 & 3.2 & \\
\hline & 1800 & 2 & 3.2 & \\
\hline & 1900 & 2 & 3.2 & \\
\hline & 2000 & 1 & 1.6 & \\
\hline & 2100 & 1 & 1.6 & \\
\hline & 2200 & 1 & 1.6 & \\
\hline & 2300 & 2 & 3.2 & \\
\hline & 0 & 2 & 3.2 & \\
\hline \multirow[t]{17}{*}{ 30-Nov } & 100 & 2 & 3.2 & Friday \\
\hline & 200 & 7 & 11.2 & \\
\hline & 300 & 6 & 9.6 & \\
\hline & 400 & 5 & 8 & \\
\hline & 500 & 4 & 6.4 & \\
\hline & 600 & 3 & 4.8 & \\
\hline & 700 & 2 & 3.2 & \\
\hline & 800 & 1 & 1.6 & \\
\hline & 900 & 1 & 1.6 & \\
\hline & 1000 & 1 & $\overline{1.6}$ & \\
\hline & 1100 & 2 & 3.2 & \\
\hline & 1200 & 2 & 3.2 & \\
\hline & 1300 & 2 & 3.2 & \\
\hline & 1400 & 1 & 1.6 & \\
\hline & 1500 & 1 & $\overline{1.6}$ & \\
\hline & 1600 & 1 & $\overline{1.6}$ & \\
\hline & 1700 & 3 & 4.8 & \\
\hline
\end{tabular}




\section{$2.2 \quad$ Fish Targets}

We anticipated that significant numbers of juvenile American shad would be passing through all routes at John Day Dam during sampling and would serve as surrogate salmonid smolts to provide data on fish velocities and trajectories for every deployment. We used the target-strength data only to assess the relative size of fish that were being sampled so we could exclude fish that were too large to be juvenile American shad.

\subsection{Evaluation Process}

For every deployment described below, we rotated installed transducers to identify the range of possible aiming angles and the optimum aiming angle for sampling at a maximum pulse-repetition rate. We identified the optimum aiming angle and maximum pulse repetition rate by examining characteristics of echoes in a real-time echogram display on a computer. Evaluation factors included a careful examination of echoes from structure, multi-path, volume reverberation, and fish. The idea was to aim each transducer so that volume reverberation, multi-path echoes, and structural echoes were minimized, (except for those from the maximum range of interest) and the pulse repetition rate was maximized. We fast-multiplexed paired in-turbine transducers to determine maximum pulse-repetition rates in case researchers wanted to take advantage of the covariance between the two sample volumes in 2002, which should reduce the overall variance in FGE estimates. We assumed that the fastest overall pulse-repetition rate that could be achieved in a fast multiplex inside an intake would exceed any rate used for slowmultiplex sampling. At the spillway, we first tried a pulse repetition rate of 30 pings/s, which we knew would be adequate though we were prepared to slow it down to avoid volume reverberation problems. The goal was to ping as fast as possible without sacrificing echogram clarity.

We evaluated fish traces at different aiming angles by visually assessing the average number of echoes per trace, trace trajectory, and ease of differentiation of traces from structure, multi-path, and noise echoes. Optimum aiming also depended on the anticipated vertical distribution of fish based upon earlier studies. At the spillway, we were particularly interested in the behavior of detected fish at ranges $>2 \mathrm{~m}$ from the transducer down to the ogee and whether any were wallowing un-entrained in the sample volume. 
Optimization of Hydroacoustic Deployments at John Day Dam 


\subsection{Results and Discussion}

\subsection{Spillway Sampling}

We determined the range of aiming angles used for spillway sampling $\left(13^{\circ}\right.$ upstream and $19^{\circ}$ downstream of vertical - Figure 3.1) by measuring one angle and calculating the other because the

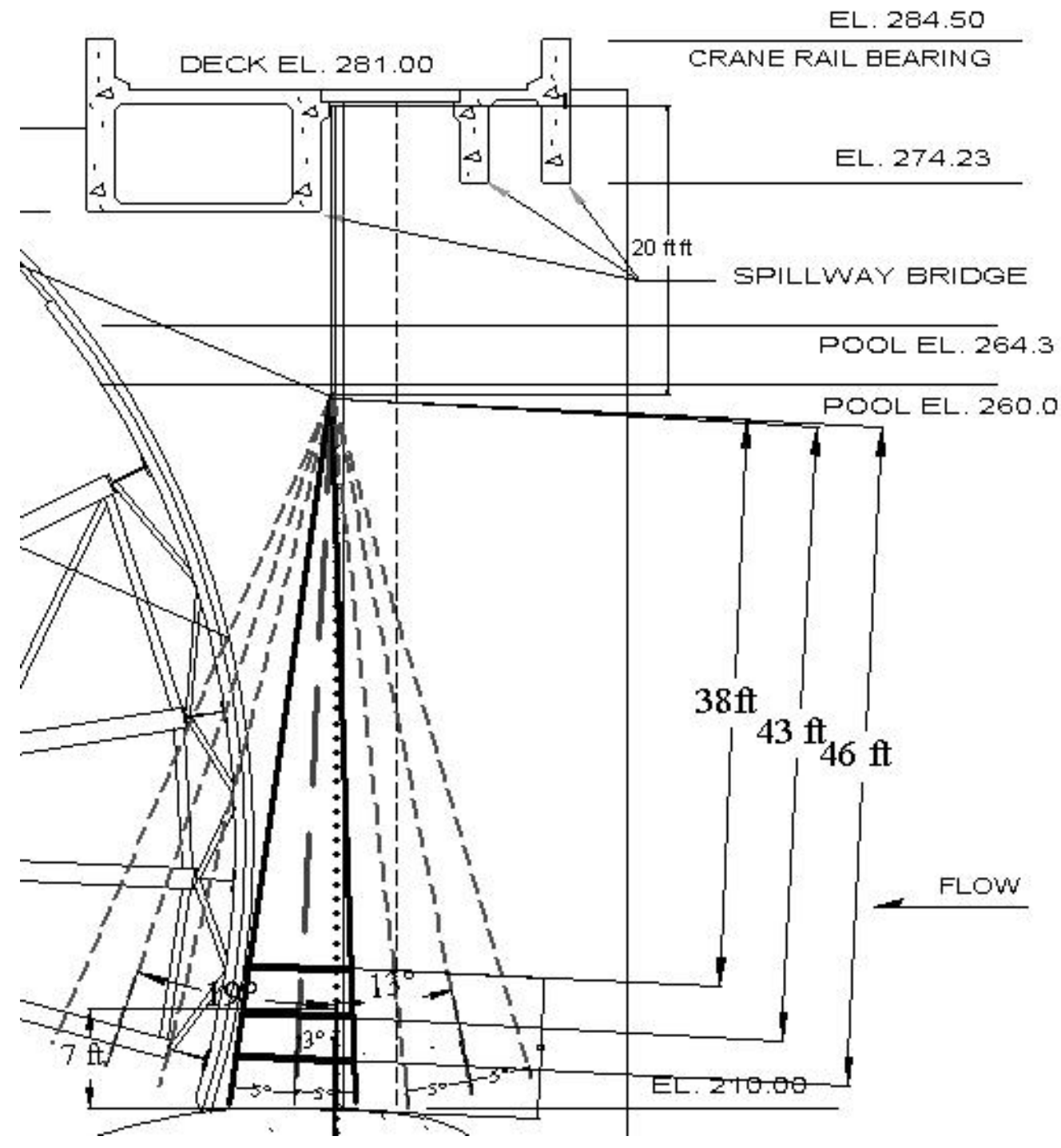

Figure 3.1. Cross-Sectional Drawing of Spill Bay 17 Showing the Range of Aiming Angles for Hydroacoustic Beams (as dashed lines) i.e., $19^{\circ}$ Downstream of Vertical to $13^{\circ}$ Upstream and the Optimum Aiming Angle (in dark solid lines). The dotted line is vertical. The 7-ft dimension was the widest gate opening tested and the three range dimensions on the right are minimum ranges for counting fish when the gate is opened $\geq 3 \mathrm{ft}$ (38-ft range), $2 \mathrm{ft}$ (43-ft range), and $1 \mathrm{ft}$ (46-ft range). 
rotator available for spillway sampling provided no remote display of the aiming angle. An aiming angle $13^{\circ}$ upstream of vertical produced the cleanest echogram with no noise or structural echoes. It was measured when the equipment was removed after sampling. We calculated the $19^{\circ}$ downstream aiming angle from that rate of rotation of the transducer (degrees/s) and the time it took to rotate the transducer from the position that produced the best echogram to the position that produced what we believed was the tightest aiming angle into the gate. With the $19^{\circ}$ downstream angle, sound traveled to the smooth curved gate and struck it with a low angle of incidence and then spread to fish in the water column and to the ogee and then back to the transducer. The resulting echogram was not noisy except for a structural echo at about $5 \mathrm{~m}$ of range, and we could not tell from the oscilloscope whether we were aimed into the gate or immediately upstream of it.

Most fish detected at ranges $<10 \mathrm{~m}$ when the transducer was aimed $13^{\circ}$ upstream were wallowing in the beam and were not entrained, even at the widest gate openings (e.g., Figures 3.2 and 3.3). The echo from the ogee was about $15 \mathrm{~m}$ of range from the transducer. Some fish deeper in the water column were entrained at the wider gate openings (e.g., Figure 3.4).

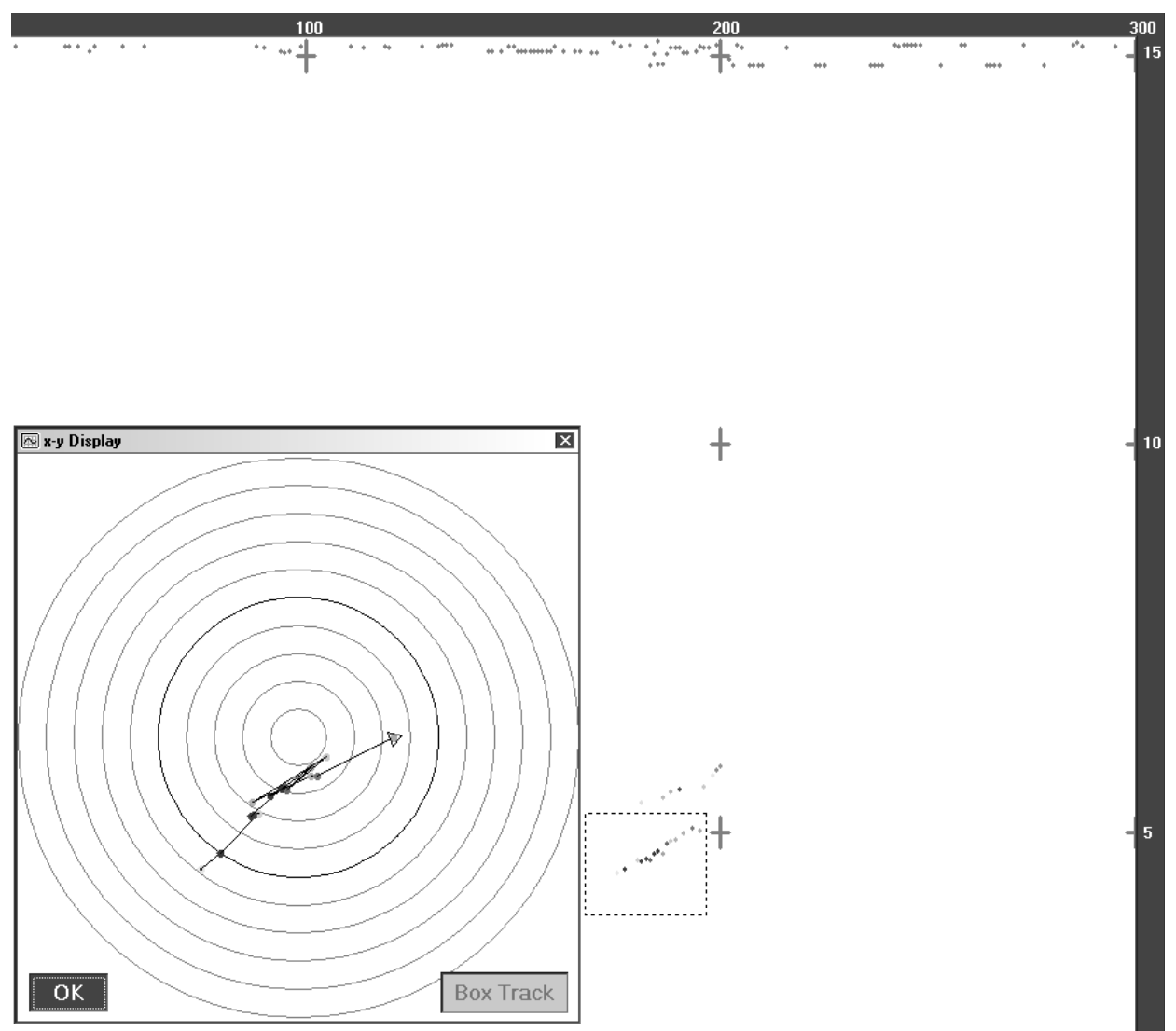

Figure 3.2. Echogram Showing a 15-Echo Fish Trace in the Dashed Box at 4 to $5 \mathrm{~m}$ from the Transducer, Which Was Aimed 13 Degrees Upstream of Vertical. Direction of fish travel across beam is shown in the $x-y$ display. A downward movement in the $x-y$ view of the beam would be downstream toward the tainter gate, which was opened $7 \mathrm{ft}$, and movement in other directions indicates a lack of entrainment. The axes are time in pings (at 30 pings/s) across the top and range in $\mathrm{m}$ from the transducer on the right. Gray echoes at about $15 \mathrm{~m}$ are from the ogee. 


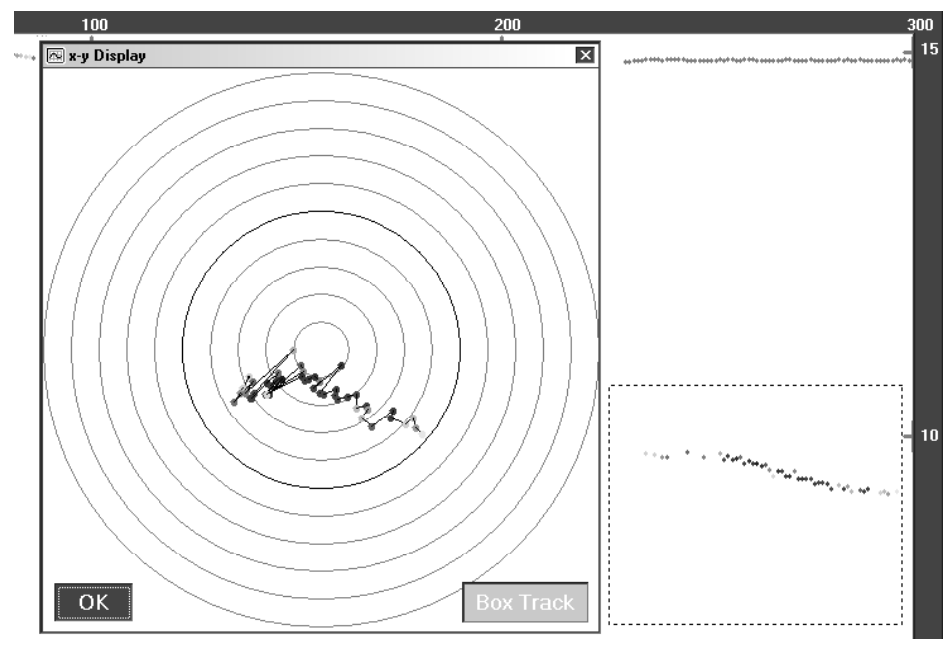

Figure 3.3. Echogram Showing a 45-Echo Trace from a $-45 \mathrm{~dB}$ Fish in the Dashed Box at about $9.5 \mathrm{~m}$ from the Transducer, Which Was Aimed 13 Degrees Upstream of Vertical. Direction of fish travel across beam is shown in the circular $x-y$ display. A downward movement in the $x-y$ view of the beam would be downstream toward the tainter gate, which was opened $7 \mathrm{ft}$, and movement in other directions indicates a lack of entrainment. The axes are time in pings (at 30 pings/s) across the top and range in $\mathrm{m}$ from the transducer on the right. Gray echoes at about $15 \mathrm{~m}$ are from the ogee.

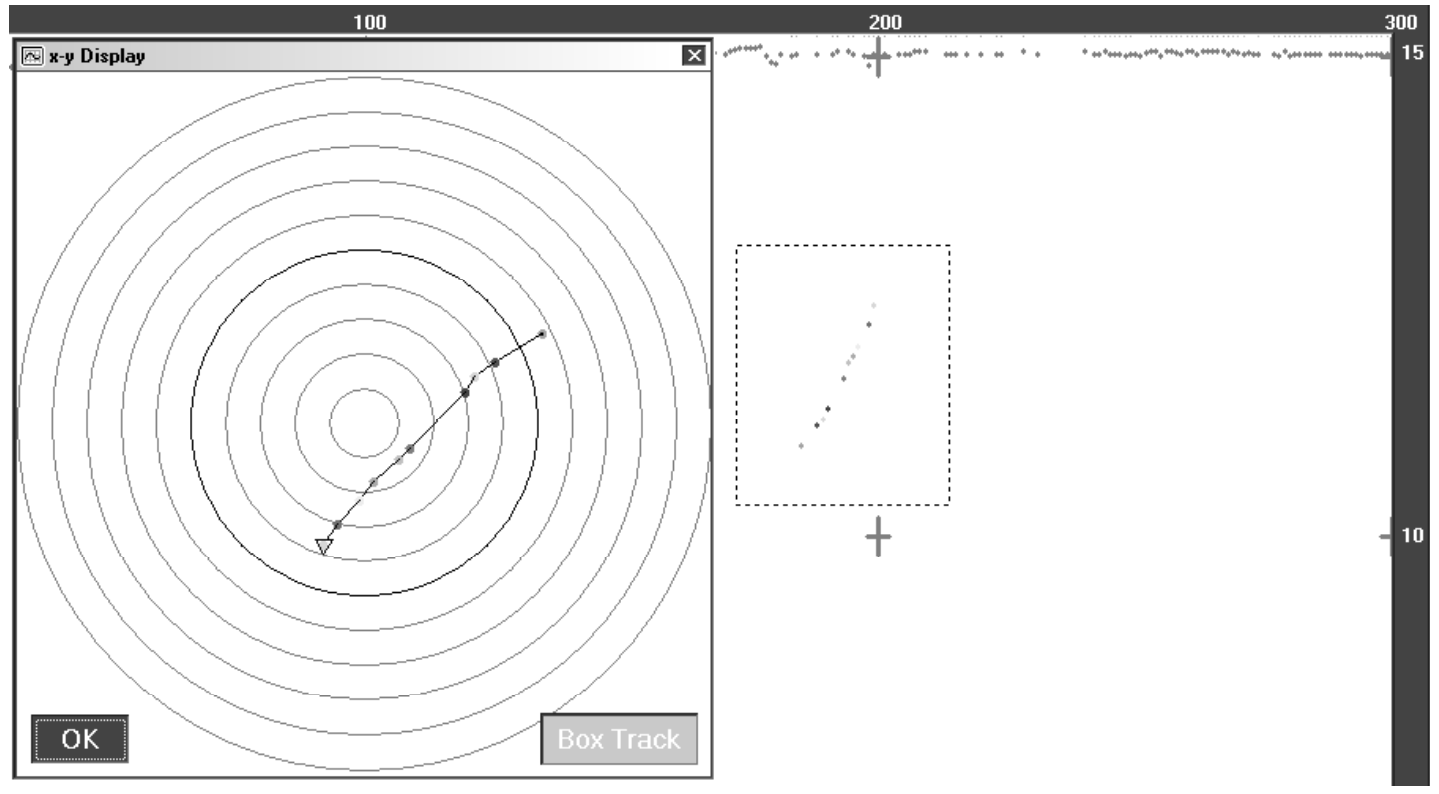

Figure 3.4. Echogram Showing a 10-echo, $-47 \mathrm{~dB}$ Fish Trace in the Dashed Box at about $11.7 \mathrm{~m}$ from the Transducer, Which Was Aimed 13 Degrees Upstream of Vertical. Direction of fish travel across beam is shown in the circular $x-y$ display. A downward movement in the $x-y$ view of the beam would be downstream toward the tainter gate, which was opened $7 \mathrm{ft}$, and movement in other directions indicates a lack of entrainment. The axes are time in pings (at 30 pings/s) across the top and range in $\mathrm{m}$ from the transducer on the right. Gray echoes at about $15 \mathrm{~m}$ are from the ogee. 
When aimed $19^{\circ}$ downstream of vertical, fish upstream of the tainter gate were detected with sound that had reflected off the gate. Therefore, it was impossible to know the true range of the fish or the ogee from the transducer or how far the fish were upstream of the gate. Phase data from the $19^{\circ}$ aiming angle appeared to be corrupted, and we could not reliably assess the direction of fish movement. Many fish detected near the ogee, even at wide gate openings, appeared to be stationary or going upstream when they should have been going downstream (e.g., Figure 3.5). Therefore, it is important to aim split-beam transducers so that the main lobe of the beam does not reflect off the gate and direction-of-travel data are reliable. An aiming angle $2^{\circ}$ downstream of vertical should preserve phase information while keeping the beam as close to the gate as possible.

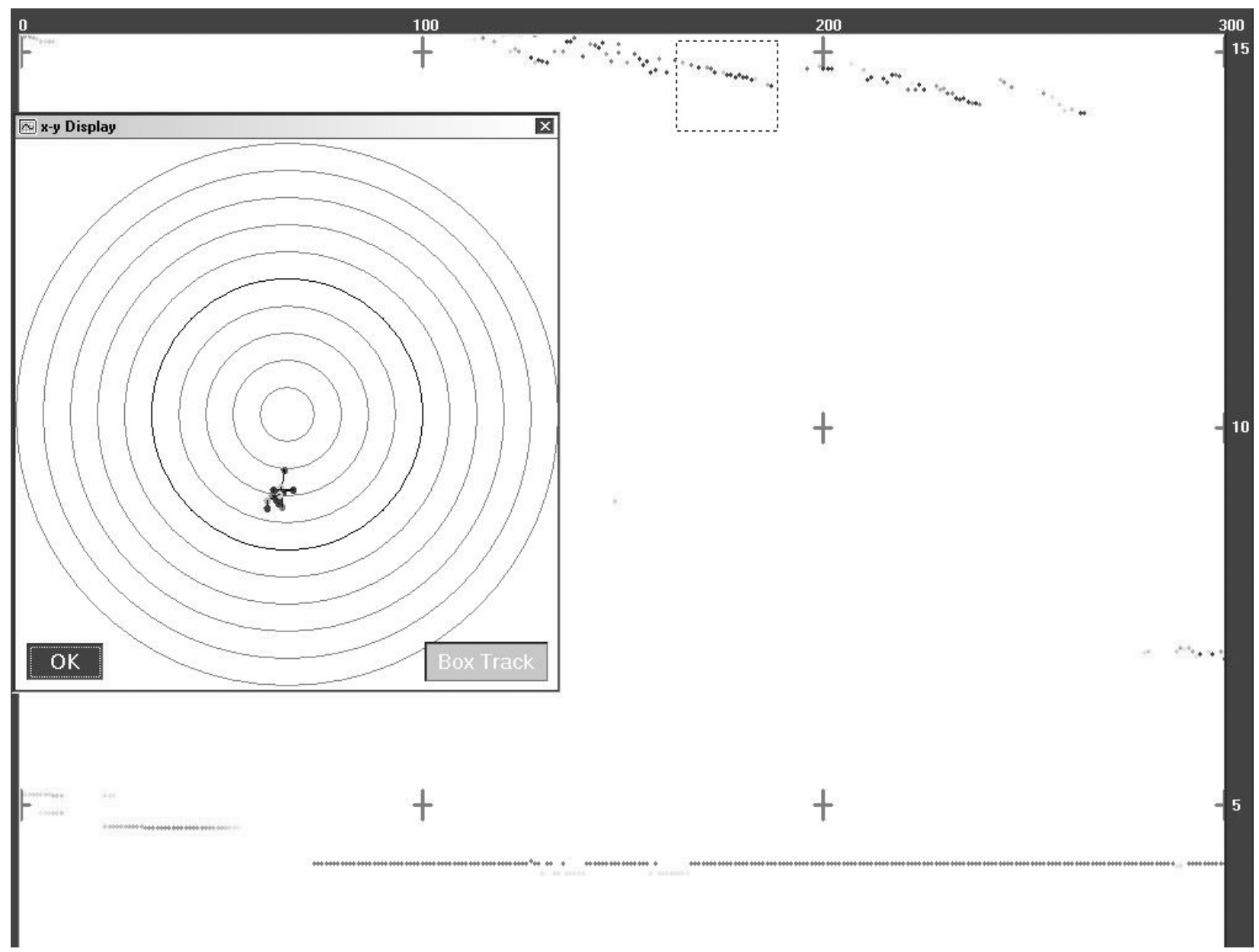

Figure 3.5. Echogram Showing a 16-Echo Fish Trace (in the dashed box) at about $14.5 \mathrm{~m}$ from the Transducer, Which Was Aimed $19^{\circ}$ Downstream of Vertical. Direction of fish travel across beam is shown in the circular $x-y$ display. Movement toward the bottom of the page in the $x-y$ view of the beam would be downstream toward the tainter gate. The gate was opened $7 \mathrm{ft}$, and the lack of movement likely indicates bad phase data resulting from sound reflecting off the smooth gate. The axes are time in pings (at 30 pings/s) across the top and range in $\mathrm{m}$ from the transducer on the right.

We rotated the transducer slowly through all possible aiming angles from $13^{\circ}$ upstream of vertical to $19^{\circ}$ downstream of vertical many times, and by knowing the rate of rotation ( 4.95 degrees/s) of the 
rotator, we were able to associate portions of echograms with aiming angles. After viewing all echogram sequences collected when the gate was opened $7 \mathrm{ft}$, we can report that all ranges from about $11 \mathrm{~m}$ to the ogee usually had minimal noise and were trackable. These trackable echograms included segments from an aiming angle that was just $2^{\circ}$ downstream of vertical, which we identified during rotation sequences as being 97 pings $(3.23 \mathrm{~s})$ after the display for the $13^{\circ}$ upstream aiming angle. At the $19^{\circ}$ downstreamaiming angle, structural echoes were detected in a narrow band at about $4.4 \mathrm{~m}$, and there was no distinct bottom echo (Figure 3.5). When aimed at about $16^{\circ}$ downstream, the echogram had a single structural band of echoes at about $7.25 \mathrm{~m}$, and a bottom echo was evident. The noisiest echograms collected had a band of noise echoes from about 6 to $10 \mathrm{~m}$ (e.g., Figures 3.6 and 3.7), but the echogram was noise free from about $11.5 \mathrm{~m}$ to the ogee, which is the range of interest for tracking fish. The noise band from 6 to $10 \mathrm{~m}$ was observed at aiming angles from about 10 degrees downstream of vertical to vertical, but it would not impede tracking of fish at ranges $>12 \mathrm{~m}$.

The optimum deployment would be one in which the pipe is mounted on the downstream wall of the stop-log-slot, the transducer is aimed as close to the gate as possible $\left(2^{\circ}\right.$ downstream of vertical), the ping-rate is 30 pings/s, and minimum ranges for counting fish are a function of the gate opening. The aiming angle is much less critical for single-beam transducers because tracking is solely by range.

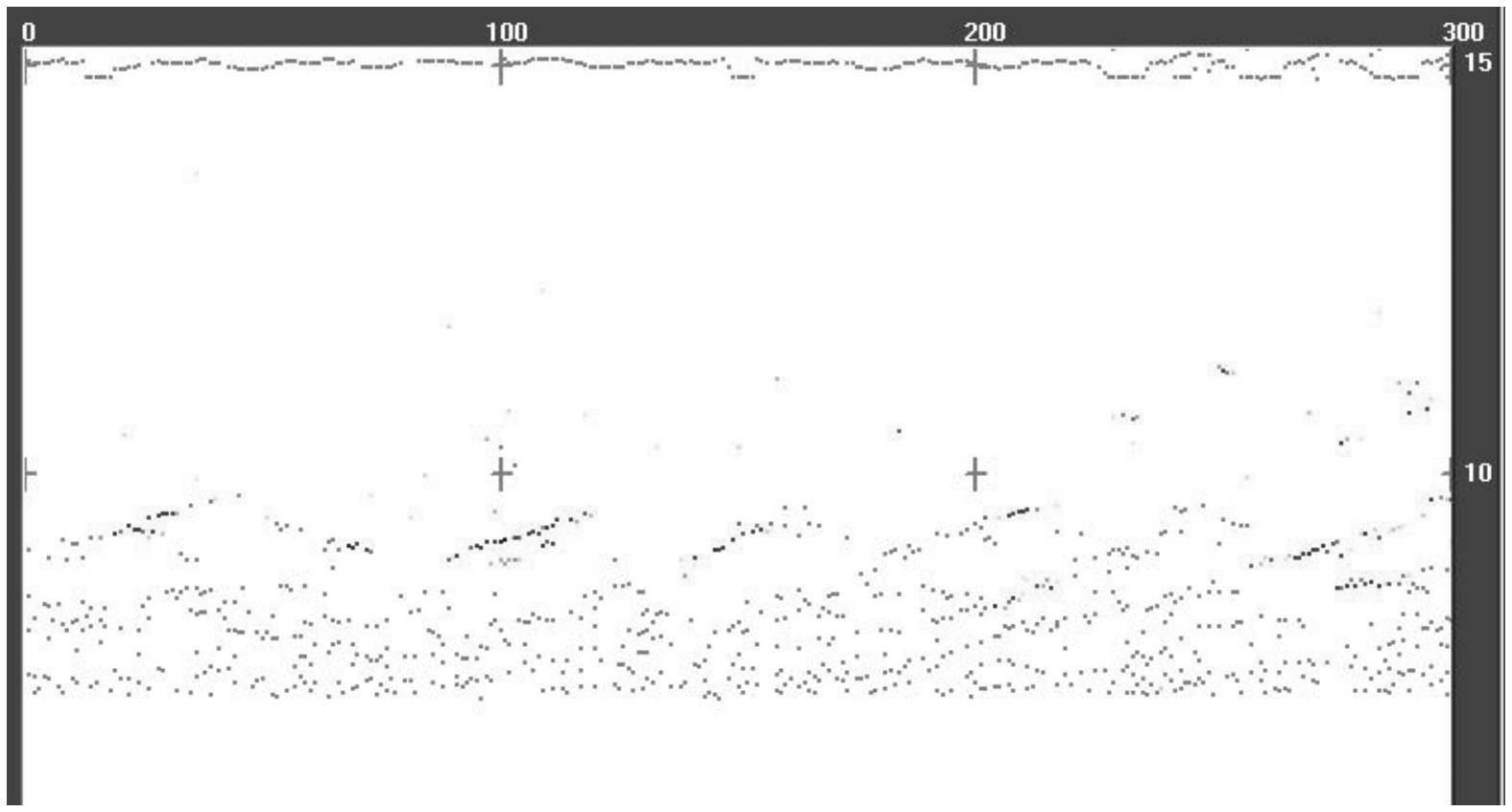

Figure 3.6. Echogram Showing Several Echo Traces from Fish at about $9.5 \mathrm{~m}$ with the Transducer Aimed $16^{\circ}$ Downstream of Vertical (just above a band of noise ranging from 6 to $9 \mathrm{~m}$ from the transducer). Examination of every potential fish trace in an $x-y$ view of the transducer beam indicated that none were moving downstream toward the tainter gate. Echogram axes are time in pings (at 30 pings/s) across the top and range in $\mathrm{m}$ from the transducer on the right. Gray echoes at about $15 \mathrm{~m}$ range were from the ogee. 


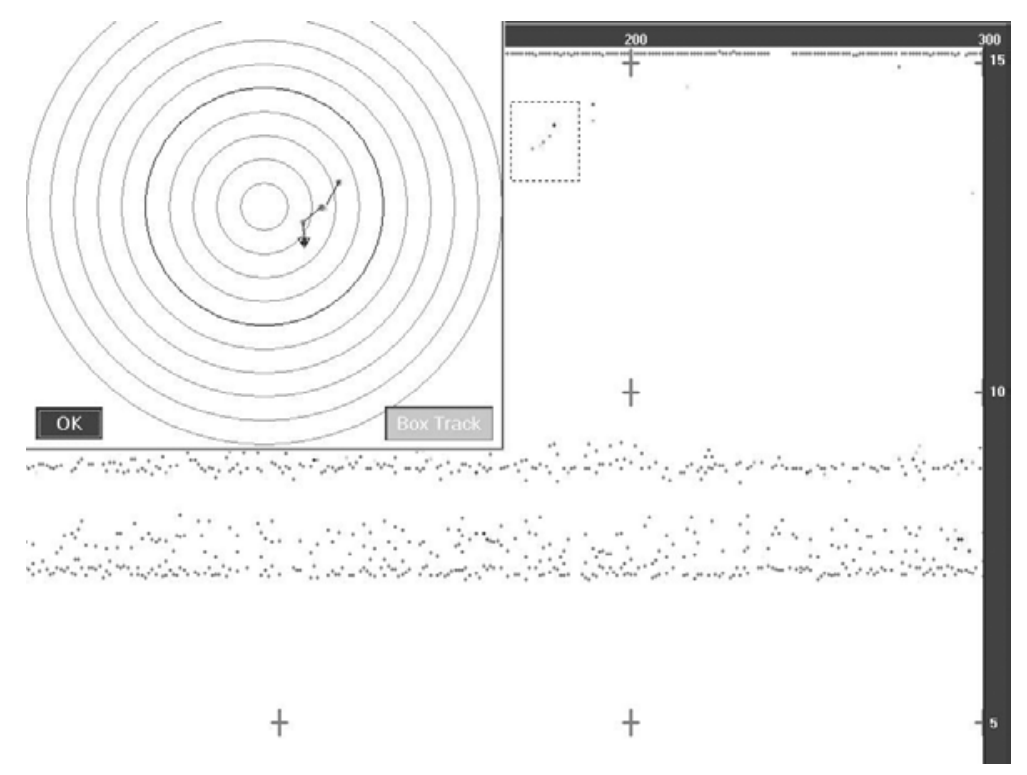

Figure 3.7. Echogram with an Echo Trace from a Fish at about $14 \mathrm{~m}$ and a Band of Noise (gray echoes) Ranging from about 6 to $9 \mathrm{~m}$ from the Transducer, Which Was Aimed $16^{\circ}$ Downstream of Vertical. The $x-y$ view of the transducer beam indicated that the fish was moving downstream toward the tainter gate. Echogram axes are time in pings (at 30 pings/s) across the top and range in $\mathrm{m}$ from the transducer on the right. Gray echoes at the $15-\mathrm{m}$ range were from the ogee.

Volume reverberation decreased slightly when we reduced pulse repetition rate from 30 to 25 pings/s and either rate appeared to be fast enough to detect fish in the high velocity areas. Given the ability to model detectability and adjust spatial expansions, the rate of $25 \mathrm{pings} / \mathrm{s}$ is recommended for the 2002 study.

The spill bay deployment identified in this study should completely eliminate multiple detections of fish by limiting the sample volume for counting fish to the deep high-discharge volume adjacent to the gate. The best way to ensure that fish are entrained is to set minimum tracking ranges that are a function of the gate opening (Figure 3.1). We recommend mounting each 10-degree spillway transducer on the bottom of the 21-ft-long, 3.5-inch-diameter pipe so that the transducer is aimed $2^{\circ}$ downstream from vertical. This aiming angle will place the beam as close as possible to the tainter gate. Greater downstream angles are possible because the tainter gate is smooth and sound will glance off of it without generating echoes greater than the sampling threshold of $-56 \mathrm{~dB} \| 1 \mu \mathrm{Pa}$ at $1 \mathrm{~m}$. This mirroring of sound provides downstream leeway for aiming single beams but would ruin phase information for split beams, so greater care will be required for aiming split beams. Angles $<2$ degrees downstream of vertical run the risk of fish diving along the gate downstream of the transducer. Aiming upstream of vertical runs the risk of detecting uncommitted fish.

Based upon the flow study and our examination of echograms, the sample volume for tracking fish should be a truncated cone with a minimum range for counting fish that is $38 \mathrm{ft}$ for gates opened $\geq 3 \mathrm{ft}, 43$ $\mathrm{ft}$ for gates opened $2 \mathrm{ft}$, and $46 \mathrm{ft}$ for gates opened $1 \mathrm{ft}$. We used CFD velocity plots (see Section 4.0) as a function of gate opening to select minimum ranges that would exclude fish in flows less than about 8 fps at any gate opening. We assumed that smolts in flows $>8 \mathrm{fps}$ are entrained. The exact minimum range 
can be fine-tuned as data are collected in 2002 without risk to the study because range filters are applied in post-processing after all data have been acquired.

\subsection{Sampling Turbines with Submerged Traveling Screens}

The optimum aiming angles for sampling above and below the STS at Intake 8c were $42^{\circ}$ and $58^{\circ}$ downstream of the plane of the trash racks (Figure 3.8). These angles were identified by rotating the transducers until strong echoes were received from the tip of the screen, which is at a shorter range than anything else inside the turbine (Figure 3.9). Next, we rotated the transducers upstream (Figure 3.10, 3.11, and 3.12) or downstream (Figure 3.13) until echoes from the screen consisted of a thin intermittent line on an echogram. The screen tip was detected even though it was outside the main 6-degree lobes of the transducer beams because it was a very large target.

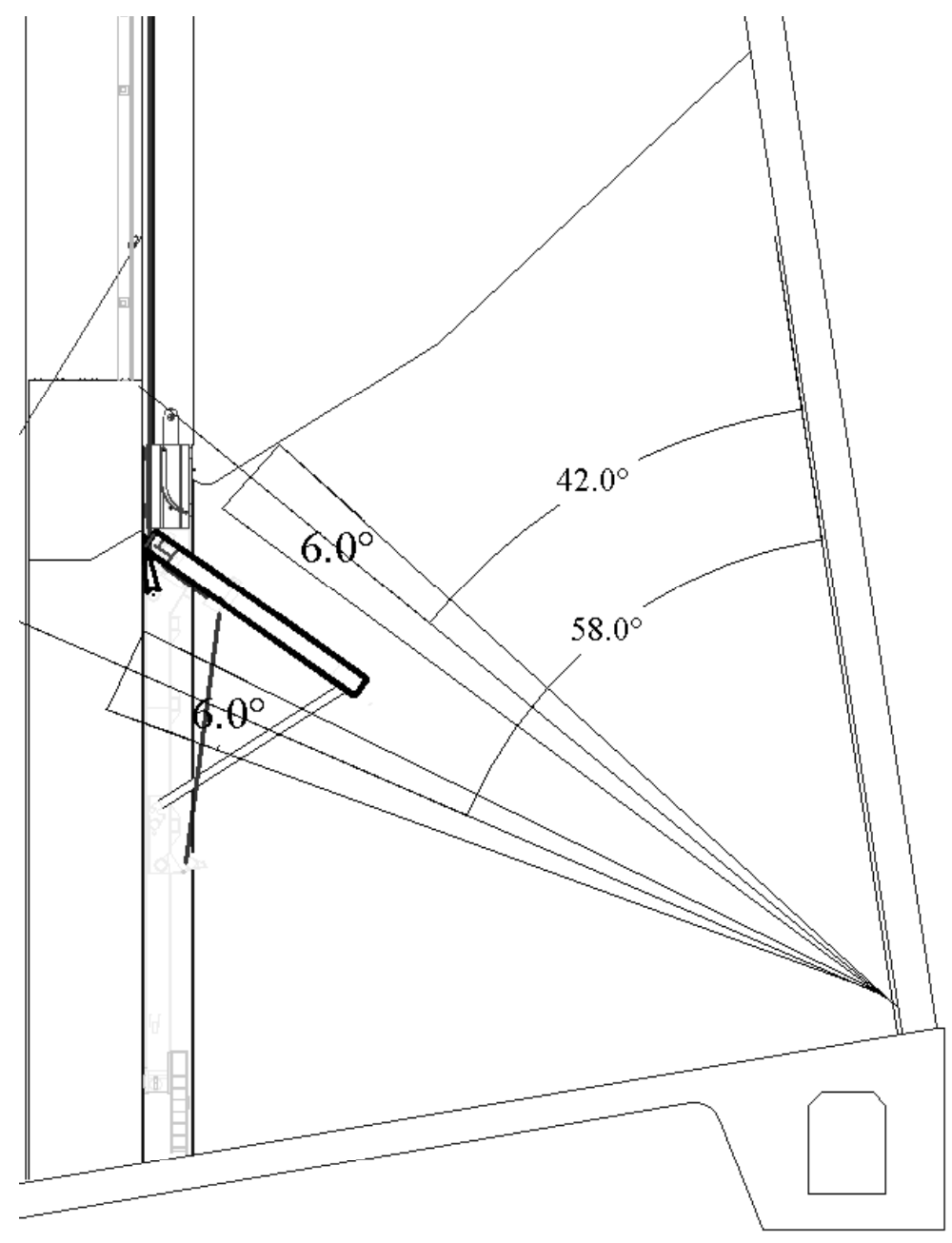

Figure 3.8. Cross Sctional View of Intake 8ㅁ with a Submerged Traveling Screen Deployed from the Gatewell Slot. Two $6^{\circ}$ split beams are shown aimed $42^{\circ}$ and $58^{\circ}$ off the plane of the trash racks. 
Differences in STS deployments, transducer mounts, mounting locations, and mounting surfaces among intakes likely account for differences between the aiming angles determined in this study and those that proved acceptable in the 2002 FPE study. Achievable aiming angles in the 2002 FPE study ranged from 33 to $42^{\circ}$ and from 58 to $64^{\circ}$. The $42^{\circ}$ and $58^{\circ}$ angles placed transducer beams as close as possible to the STS but provided no leeway for error, which is needed when divers are installing and must manually re-aim many transducers. For future FPE studies, we recommend initially installing transducers with more conservative aiming angles such as $36^{\circ}$ and $63^{\circ}$ so that few transducers will need to be reaimed.

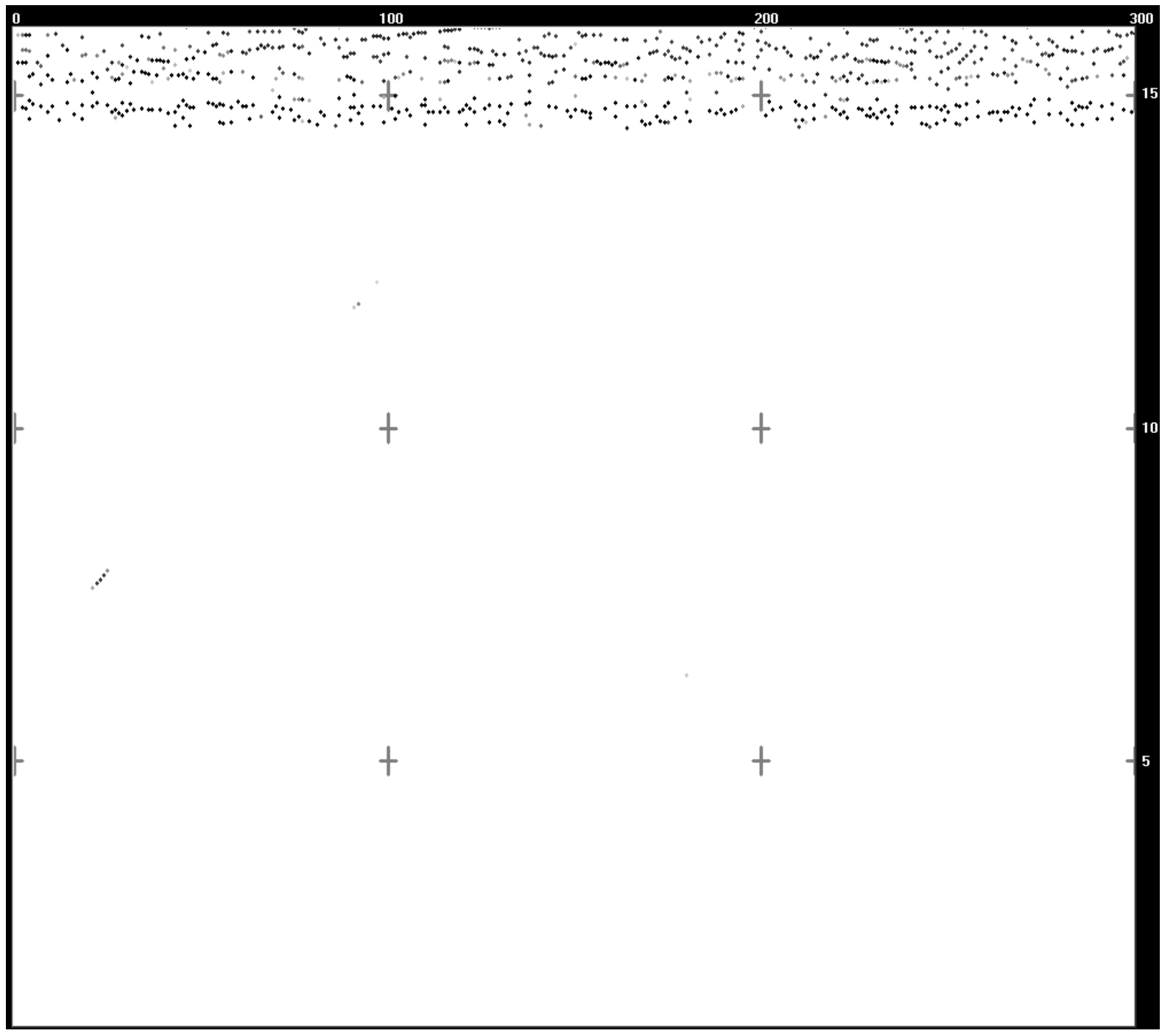

Figure 3.9. Echogram from a Transducer Aimed Directly at the Screen Tip at a Range of about $14.8 \mathrm{~m}$. Note the steeply sloped fish trace at about Ping 20 and $7.5 \mathrm{~m}$ of range. Echogram axes are time in pings (at 15 pings/s) across the top and range in $\mathrm{m}$ from the transducer on the right. 
The advantage of detecting the screen tip in the slant range of the upstream beam is that it provides a convenient visual reference for classifying guided and unguided fish with a single beam. Figures 3.9, $3.10,3.11$, and 3.13 show fish detected from 1 to $14.7 \mathrm{~m}$ from the transducer, which could be classified as unguided and fish detected from 15.04 to $19.5 \mathrm{~m}$, which could be classified as guided (Figure 3.10 and 3.12).

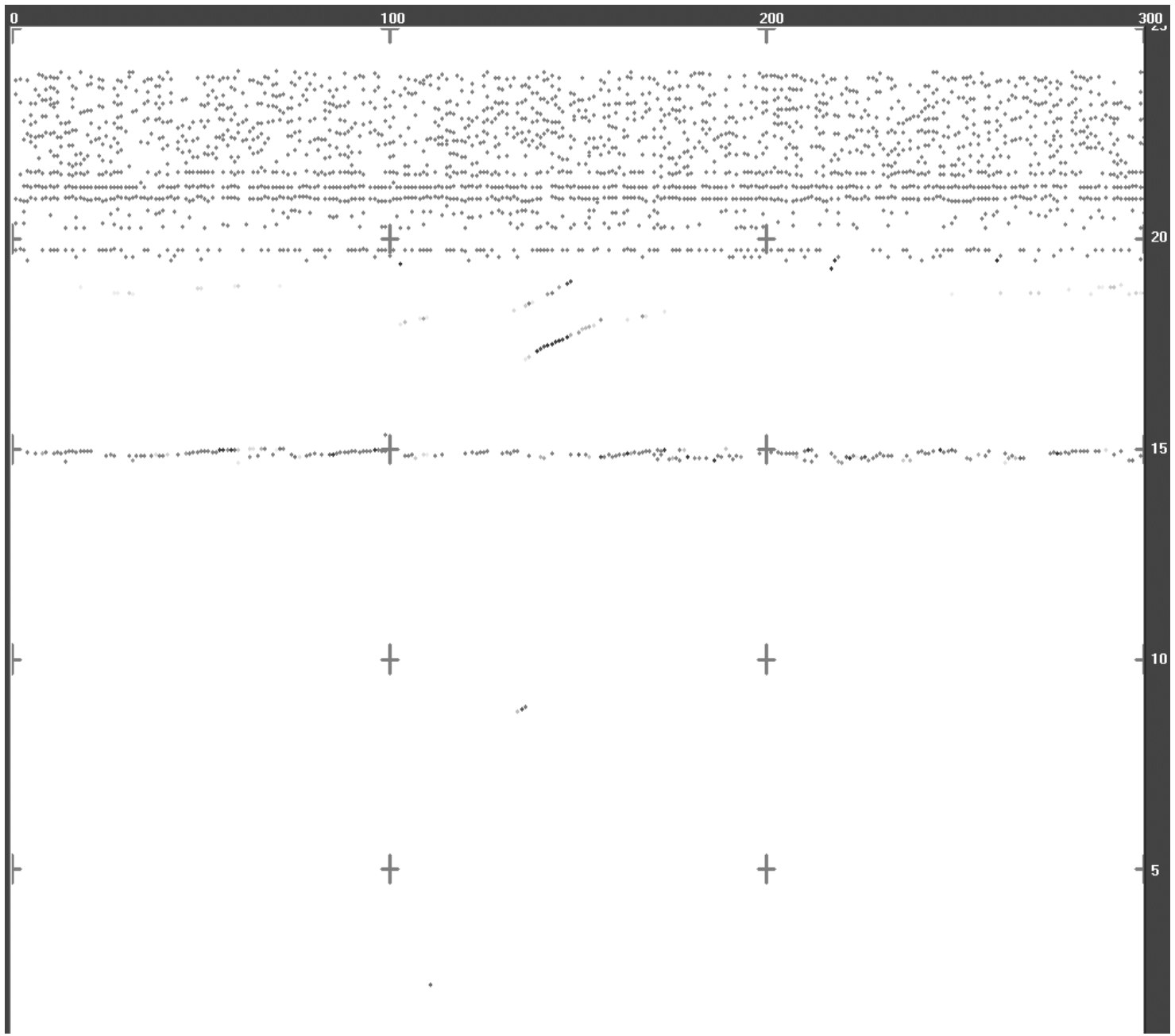

Figure 3.10. Echogram from a Transducer Aimed $42^{\circ}$ Downstream of the Trash-Rack Plane Showing Traces of One or Two Guided Fish Passing Above the Tip of the Screen (at $15 \mathrm{~m}$ ) and Below the Intake Ceiling (at $19.6 \mathrm{~m}$ ). Echogram axes are time in pings (at 15 pings/s) across the top and range in $\mathrm{m}$ from the transducer on the right.

A second and perhaps better estimate of unguided fish passage can be obtained from the beam sampling downstream of the screen at ranges from 1 to $17.3 \mathrm{~m}$ (Figure 3.13). This sample should include fish striking the screen tip and passing below it as unguided and therefore may better represent the fate of fish near the screen tip. 


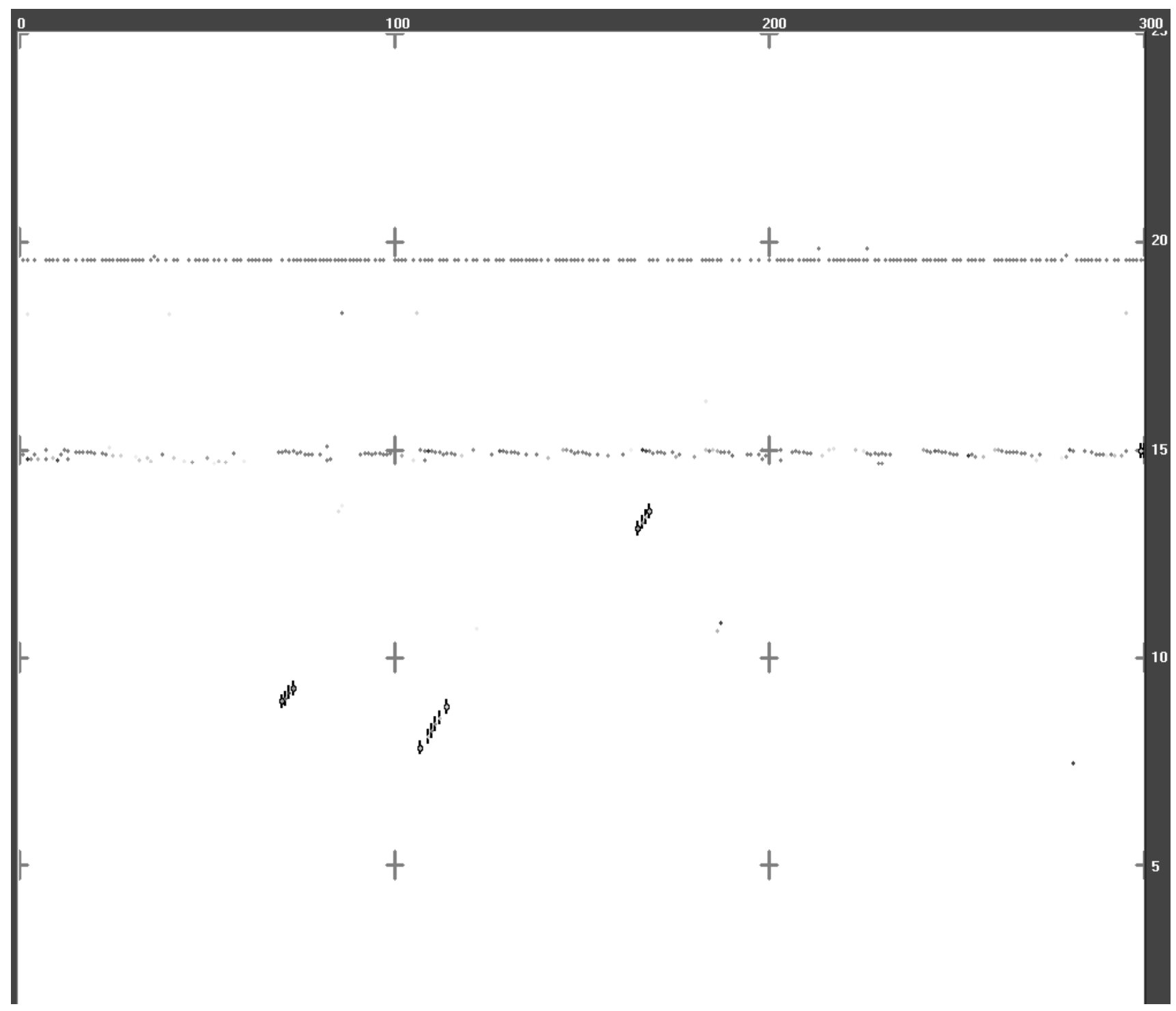

Figure 3.11. Echogram from a Transducer Aimed $42^{\circ}$ Downstream of the Trash-Rack Plane Showing Steep Traces of Three Unguided Fish Passing Short of the Range of the Screen Tip (at about $15 \mathrm{~m}$ ) on the Upstream Beam for Sampling Guided Fish (see Figure 3.8). The intake ceiling upstream of the screen tip was about $19.6 \mathrm{~m}$. Echogram axes are time in pings (at 15 pings/s) across the top and range in $\mathrm{m}$ from the transducer on the right.

After sampling in 2002, we should be able to compare unguided estimates from both beams and determine with confidence whether the downstream beam is truly necessary. Sampling with one beam and partitioning guided and unguided fish by range has distinct advantages over using two beams, one upstream and one downstream of the screen. The primary advantage is that fast multiplexing would not be required and a single upstream transducer could be sampled at a much higher ping rate. The higher ping rate would improve detectability, and simultaneous sampling of guided and unguided fish would reduce the variance of FGE estimates by including a covariance term in the calculations. Another advantage would be that the number of transducers required for sampling one intake could either be cut in two or the spatial sampling coverage at each intake could be doubled. However, if the estimate of 
unguided fish were significantly higher in the downstream beam than in the upstream beam, it may not be wise to drop the downstream beam for sampling unguided fish. We do not believe the comparison of unguided estimates from the two beams should be made using juvenile shad data collected in this study because of potential differences in detectability between shad and salmon

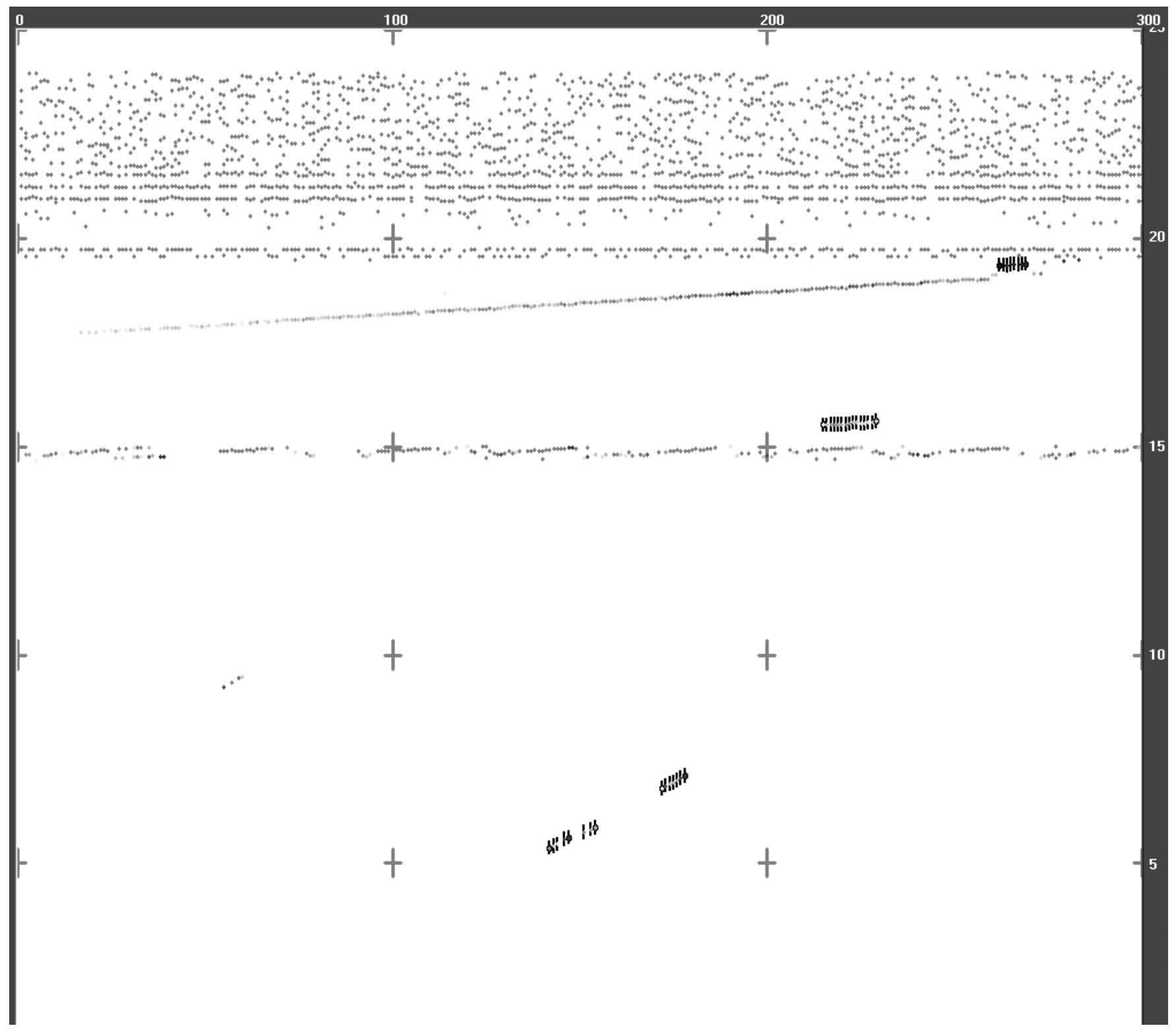

Figure 3.12. Echogram from a Transducer Aimed $42^{\circ}$ Downstream of the Trash-Rack Plane Showing Steep Traces of Two Unguided Fish Passing 6 to $7 \mathrm{~m}$ Short of the Screen Tip. Also shown are two guided fish passing between the screen tip at $15 \mathrm{~m}$ and the ceiling at about $19.6 \mathrm{~m}$, and a long line of cross talk changing range from about 18 to $19 \mathrm{~m}$ and from ping 20 to ping 270. Echogram axes are time in pings (at 15 pings/s) across the top and range in $\mathrm{m}$ from the transducer on the right. 
At the time we were sampling at Unit 8, some electronic cross talk was apparent in the echograms from both the upstream and downstream transducers. The cross talk consisted of consecutive echoes that gradually and uniformly increased in range for more than 50 pings (See Figures 3.12 and 3.13). We tried to eliminate the cross talk by slowing down the ping rate and even slow multiplexing the transducers but it was independent of our sampling methods. It may have been generated by instruments used to sample flow in Unit 9 or by $60 \mathrm{~Hz}$ background noise at the powerhouse. Consistent cross talk should not be a problem for manual trackers or the autotracker as long as it is not intermittent. We have successfully dealt with it previously at other dams.

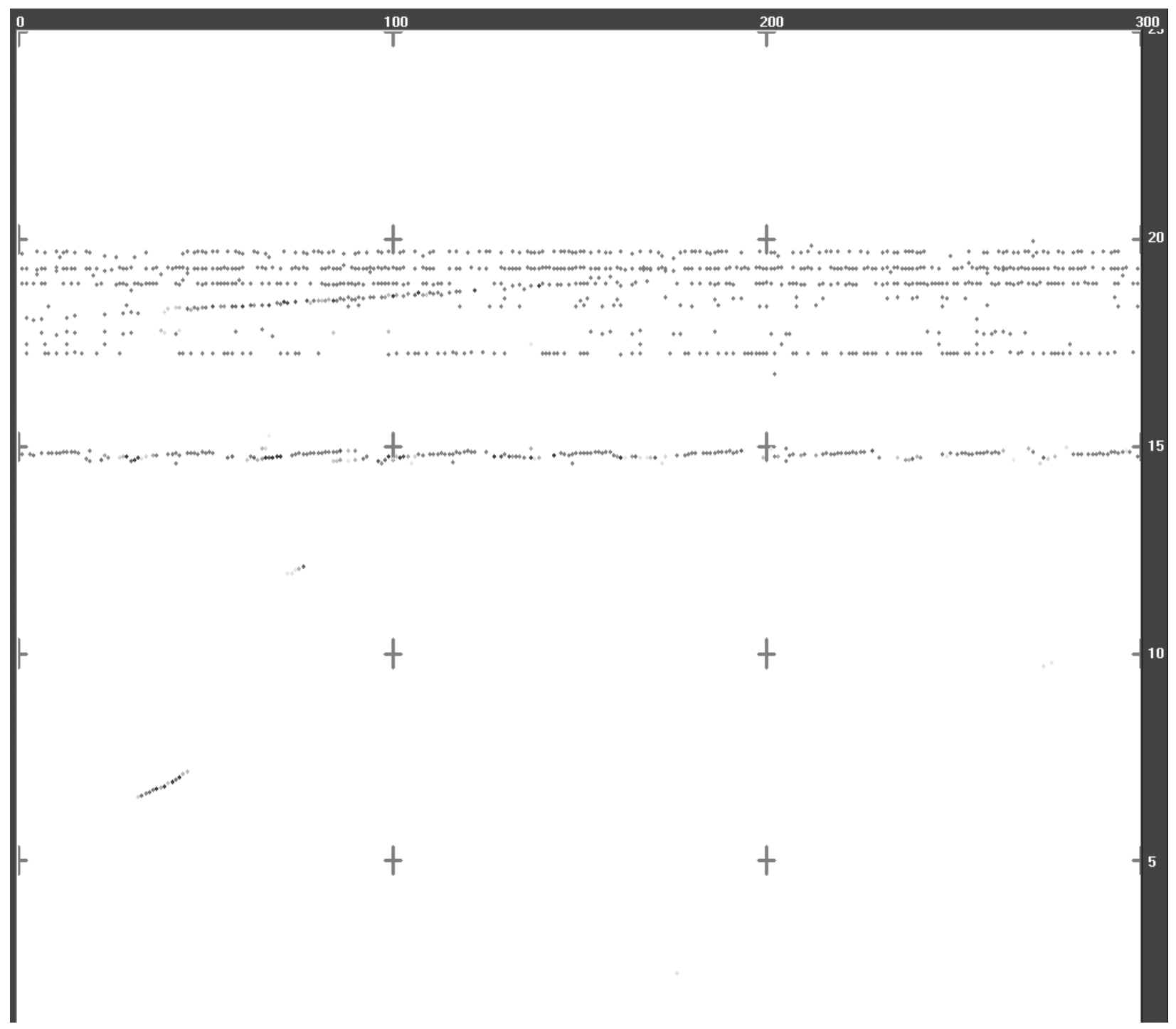

Figure 3.13. Echogram from a Transducer Aimed $58^{\circ}$ Downstream from the Trash-Rack Plane Showing Steep Traces of Two Unguided Fish Passing Short of the Range of the Screen Tip (at about $15 \mathrm{~m}$ ) in the Downstream Beam for Sampling Unguided Fish. The range to the first structure downstream of the screen tip was about $17.3 \mathrm{~m}$. Echogram axes are time in pings (at 15 pings/s) across the top and range in $\mathrm{m}$ from the transducer on the right. Cross talk was evident from about ping 40 to ping 110 at a range of about 18 to $19 \mathrm{~m}$. 
After the in-turbine transducers in Intake 8ㅁ were removed, divers tested newly designed transducer mounts (Figure 3.14) that were narrow enough to pass through the space between vertical trash-rack bars from the forebay. The divers successfully bolted the mounts onto a horizontal shelf of the trash rack by reaching through vertical trash-rack bars above and below the shelf and tightening a nut on the bottom of a bolt that extended through a drain hole. These mounts should eliminate most of the penetration dives previously required to install in-turbine transducers at John Day Dam.

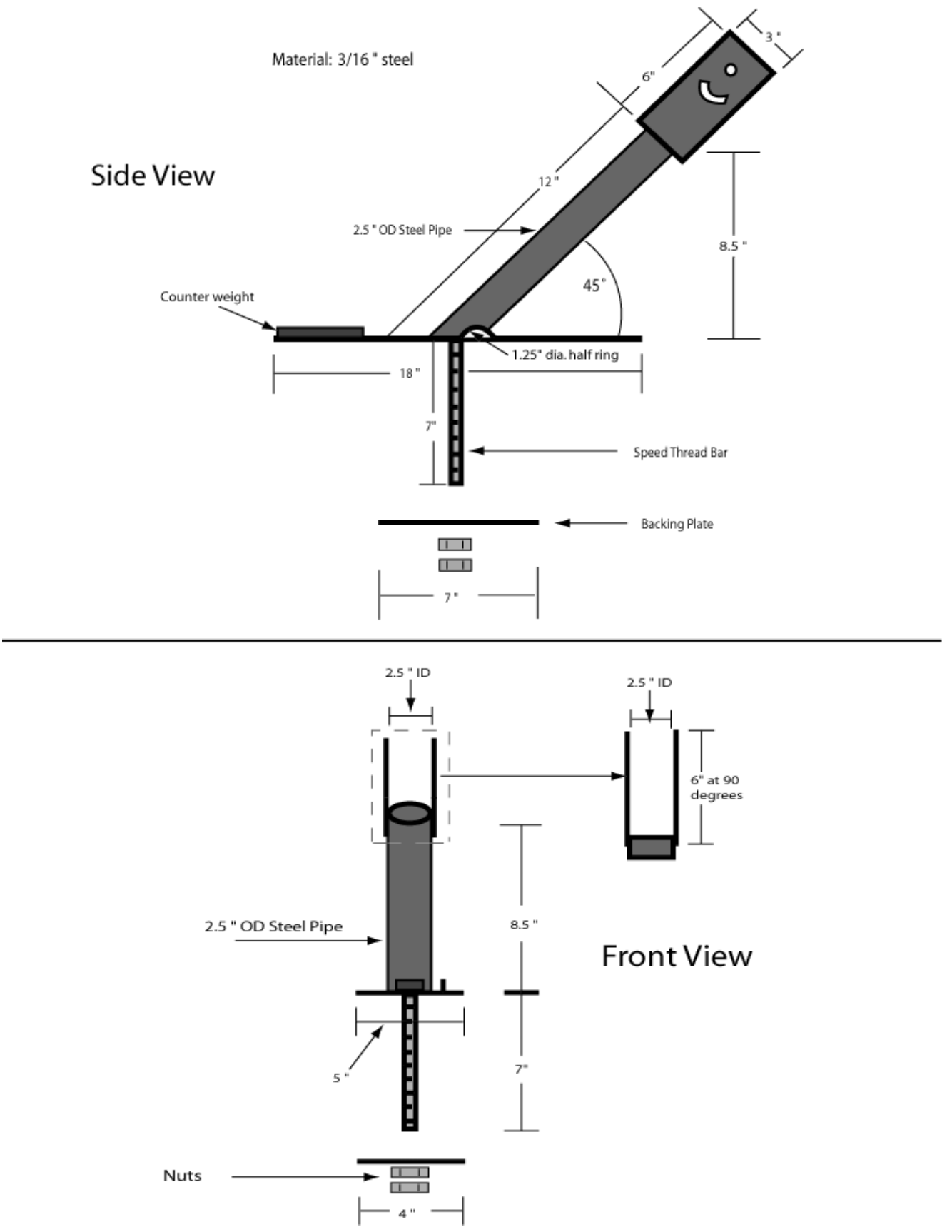

Figure 3.14. Side and Front Views of a New Transducer Mount for Trash-Rack Deployments at John Day Dam 
The other critical element for successful installation of transducers from the forebay is cable routing. A new approach was tested for routing cable to the transducers and proved to be successful. Divers routed grade-40, 2-inch OD, PVC conduit vertically through drain holes in horizontal members of six trash racks (Figure 3.15). Clamps around the top and bottom of the conduit were of a larger diameter than the drain hole and held the conduit in place vertically. The conduit should provide excellent abrasion protection for cables from the top of the trash rack to just above the transducer mount.

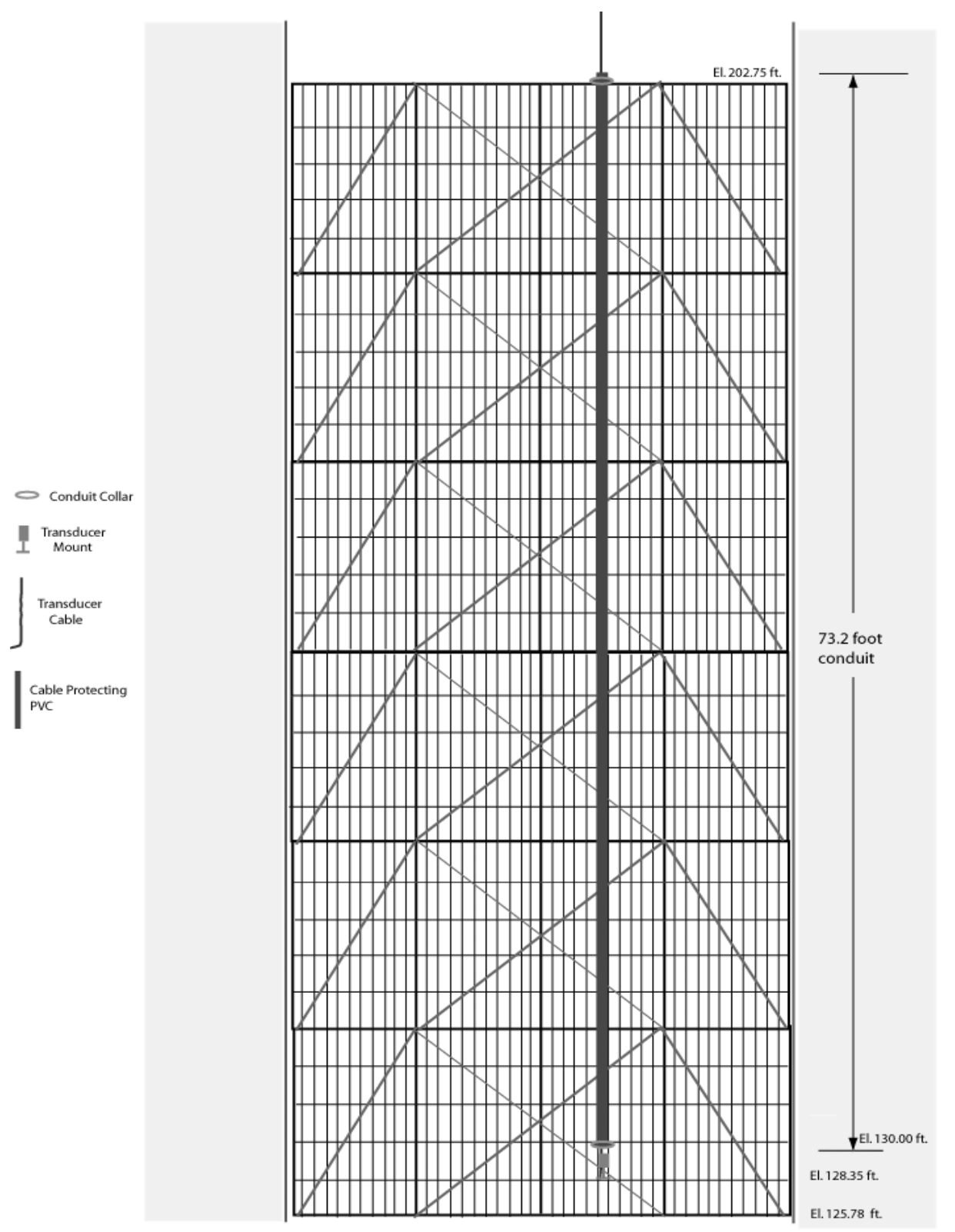

Figure 3.15. Front View of a Turbine Intake at John Day Dam Showing Six Trash Racks and the Deployment of $73.2 \mathrm{ft}$. of PVC Pipe Conduit through Drain Holes. 


\subsection{Computational Fluid Dynamics Model Analysis}

A three-dimensional (3-D) computational fluid dynamics (CFD) model of the John Day Spillway was applied to quantitatively understand velocity fields upstream of the tainter (or radial) gate. This model used the commercial program Flow-3D to solve the Reynolds-averaged Navier-Stokes equations to simulate transient free-surface flows. To reduce the computational effort required to operate the CFD model, the model domain was reduced to a single two-dimensional (2-D) plane that passed through the centerline of a spillway bay. This approximation is appropriate for understanding hydraulic phenomenon in close proximity to the tainter gate centerline; however, differences between the CFD model and prototype would be expected near the piers on either side of the gate. Several 3-D phenomena occur near these side piers, including sometimes large vortices, which will not be captured by this 2-D model. In addition, far upstream of the gate, the lateral flow component has been shown to be significant depending upon powerhouse and spillway conditions. Therefore, if results far upstream of the gate are required, a 3D model of the forebay that incorporates these lateral flows should be applied.

\subsection{Model Boundary Conditions and Assumptions}

The boundary conditions for the model were relatively straightforward. The forebay elevation for all simulations was fixed at $263.3 \mathrm{ft}$ (datum was sea level), corresponding to the approximate elevation recorded during the measurement period. The upstream boundary was of a fixed velocity type, computed by dividing the gate-opening-appropriate discharge by the upstream cross-sectional area. Discharges were obtained from a rating curve supplied by the Hydraulic Design Branch of the U.S. Army Corps of Engineers - Portland District. The discharge values for forebay elevation $263.3 \mathrm{ft}$ are shown in Table 4.1.

Wall shear stresses were computed by the CFD model and boundary coefficients were set at values appropriate for smooth concrete. Flow turbulence was computed using an approach based upon the Renormalized Group (RNG) method. The downstream boundary condition was set as an "outflow" type, which allowed for outgoing waves to leave the domain without reflection.

Once the boundary conditions were set, the model was simulated from an initial quiescent state. The model was then operated until changes in volume within the simulated domain were less than $0.1 \%$. At this point in the simulation downstream discharges were confirmed to come to a dynamic pseudo-steady state with a time-averaged mean discharge equal to the constant upstream boundary. 
Table 4.1. Discharge Under a Single John Day Spillway Gate at a Forebay Elevation of $263.3 \mathrm{ft}$

\begin{tabular}{|c|c|}
\hline Gate Opening & Discharge (cfs) \\
\hline $1 \mathrm{ft}$ & 1,569 \\
\hline $2 \mathrm{ft}$ & 3,384 \\
\hline $3 \mathrm{ft}$ & 5,190 \\
\hline $4 \mathrm{ft}$ & 7,001 \\
\hline $5 \mathrm{ft}$ & 8,795 \\
\hline $6 \mathrm{ft}$ & 10,596 \\
\hline $7 \mathrm{ft}$ & 12,393 \\
\hline $8 \mathrm{ft}$ & 14,185 \\
\hline $9 \mathrm{ft}$ & 15,971 \\
\hline $10 \mathrm{ft}$ & 17,750 \\
\hline
\end{tabular}

\subsection{CFD versus 1:25 Scale Physical Model}

Results from the 6-ft gate opening CFD simulation were compared to physical model results presented in NHC (1999) for the Gate Stop 7 test. Because the matrix of physical model results were based upon gate "stops," an exact comparison for much of the physical model data is not possible because these stops do not correspond to the gate openings used in the rating curve. However, the NHC Gate Stop 7 test discharge corresponds roughly to a rating curve gate opening of $5.8 \mathrm{ft}$, so results for this one test were expected to be similar.

The CFD domain results were interpolated at the physical model data collection locations. A graphical comparison of both numerical and physical model results is presented in Figure 4.1. CFD and physical model results closely match in both magnitude and direction at most locations. The exception is the one reading nearest the gate opening. At this location, the CFD and physical model velocity vectors point in slightly different directions; however their magnitudes are in close agreement (physical model = $13.3 \mathrm{ft} / \mathrm{s}$ versus numerical model $=14.9 \mathrm{ft} / \mathrm{s}$, or a difference of $12 \%$ ).

Figure 4.2 presents a comparison of velocity magnitudes between the physical and CFD model results. Results between the two data sets match with a linear regression $\mathrm{R}^{2}$ of 0.977 . Standard deviations of the physical model results were not provided in the report, so they cannot be compared to the differences between model results. Differences between the two datasets are quite small, however, and although not presented in the NHC report, transient fluctuations and measurement errors would be expected to fall within the range of the differences between CFD and physical model results. 


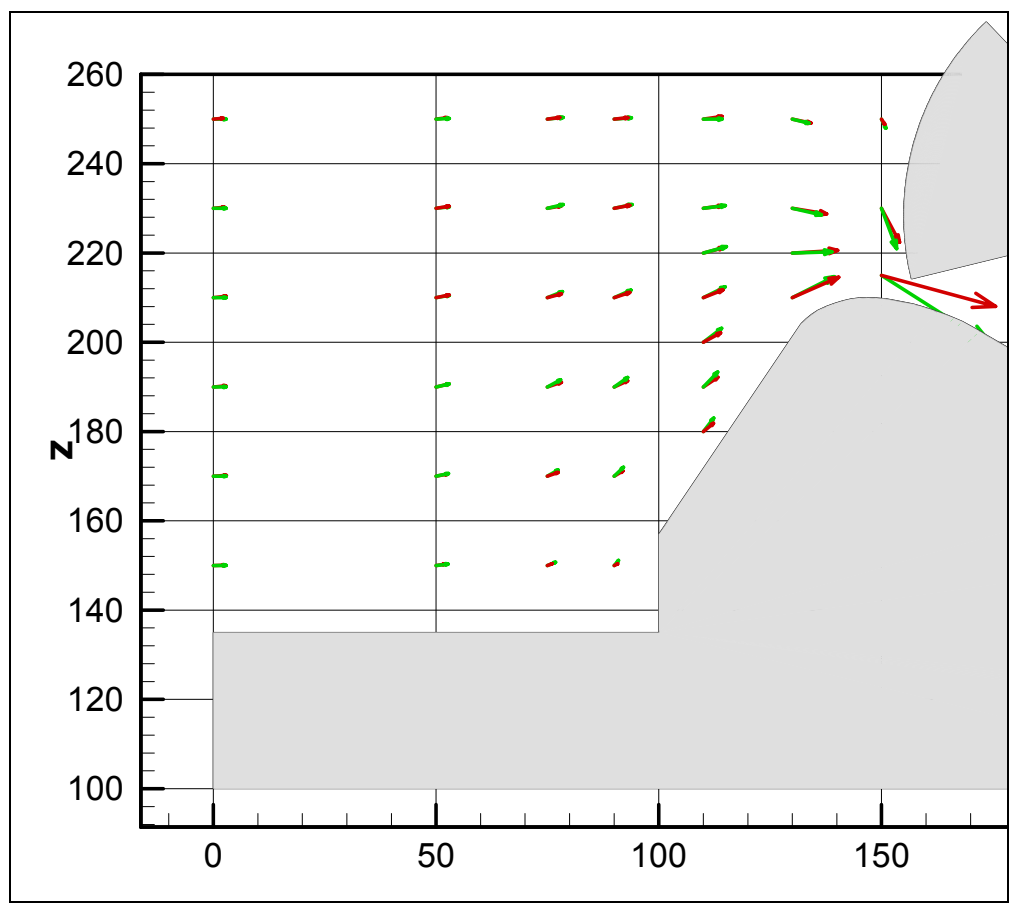

Figure 4.1. CFD versus Physical Model Results. CFD velocity vectors are shown in green and physical model velocity vectors are shown in red. The axis scales are in feet.

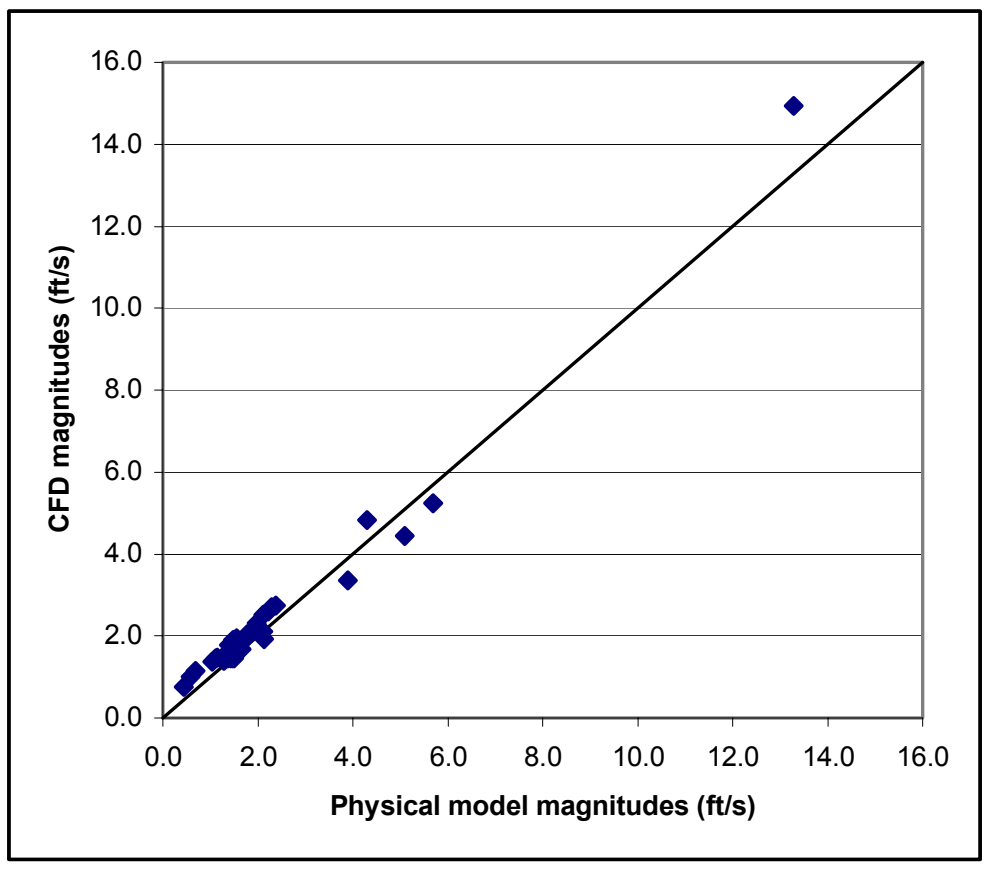

Figure 4.2. Comparison between CFD and Physical Model Velocities. Perfect agreement of the two data sets would produce points that fall along the 45-degree line. Results match with a linear regression $R^{2}$ of 0.98 . 


\subsection{CFD Results by Gate Opening}

Figure 4.3 displays contours of water velocity magnitude upstream of a single spillway bay at John Day Dam. The lower right gray object on each graph is the spillway crest while the gray object in the upper right is the tainter gate. Velocity magnitude contours are scaled by color from blue $(0 \mathrm{ft} / \mathrm{s})$ to red (30 ft/s and above). The black velocity contour lines have been placed in $3 \mathrm{ft} / \mathrm{s}$ increments, starting at 3 $\mathrm{ft} / \mathrm{s}$ with the left-most line and increasing to $30 \mathrm{ft} / \mathrm{s}$ near the gate. The vertical domain extends from elevation $185 \mathrm{ft}$ to $263 \mathrm{ft}$ (water surface elevation for the simulations), and the horizontal domain spans approximately $80 \mathrm{ft}$.

$1 \mathrm{ft}$ gate opening

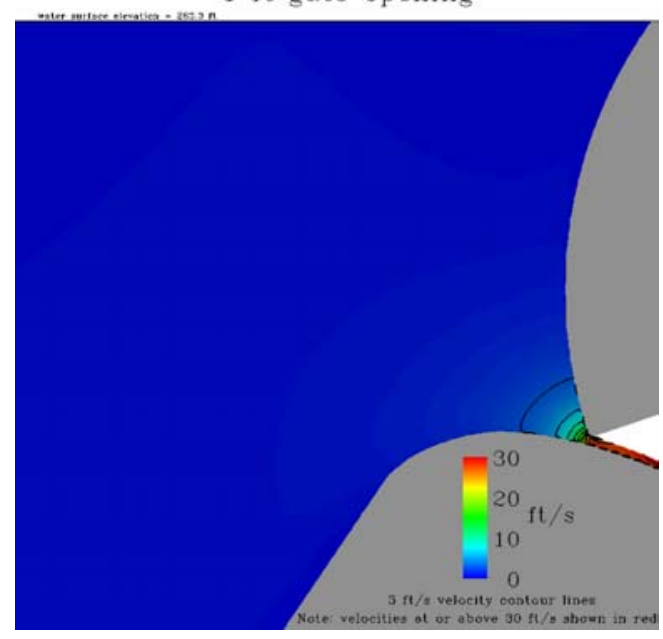

$3 \mathrm{ft}$ gate opening
$2 \mathrm{ft}$ gate opening

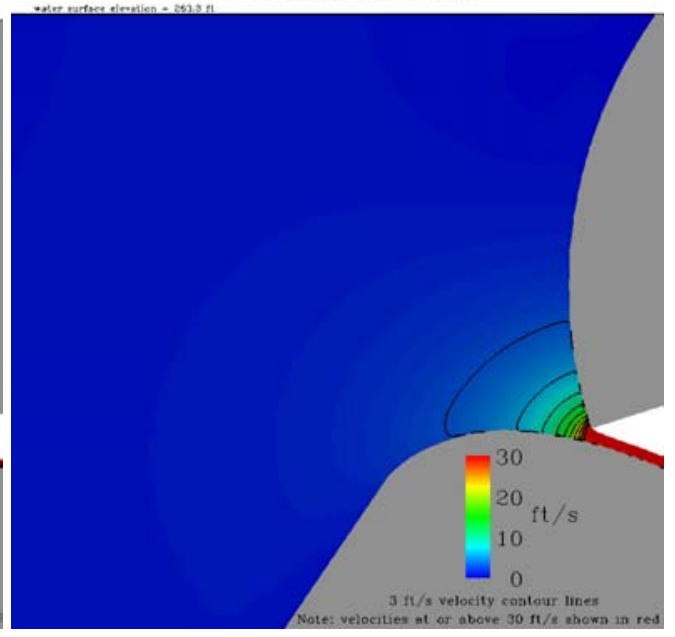

$4 \mathrm{ft}$ gate opening
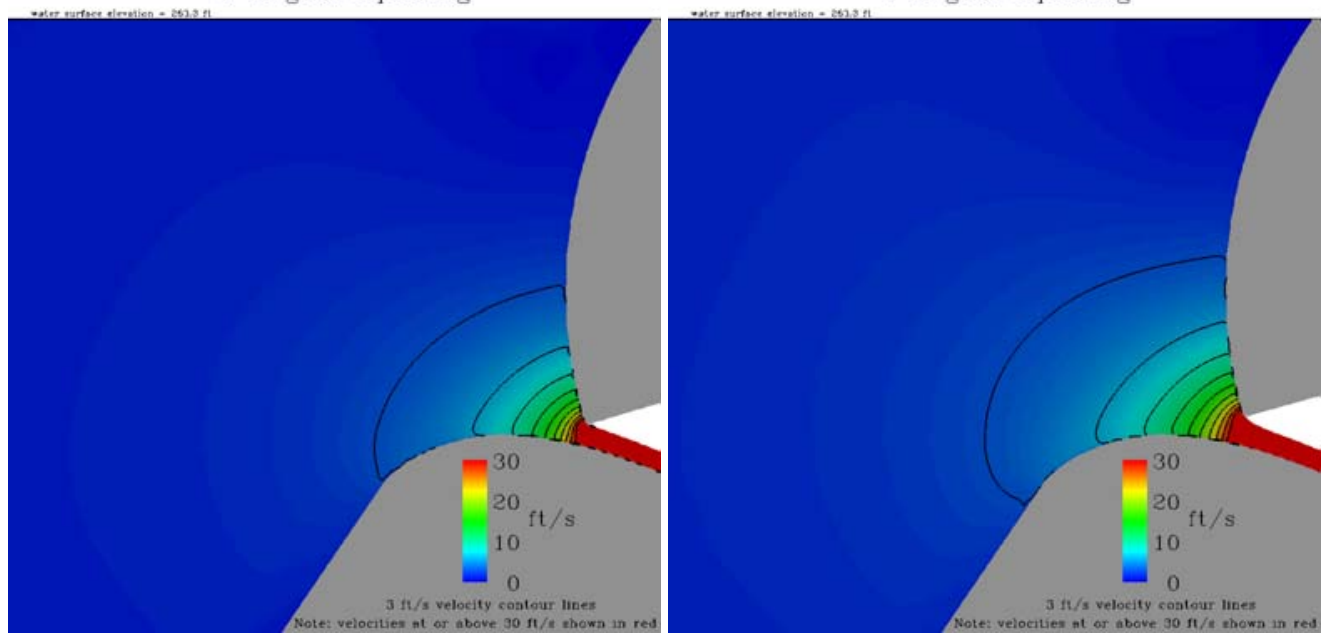
$5 \mathrm{ft}$ gate opening

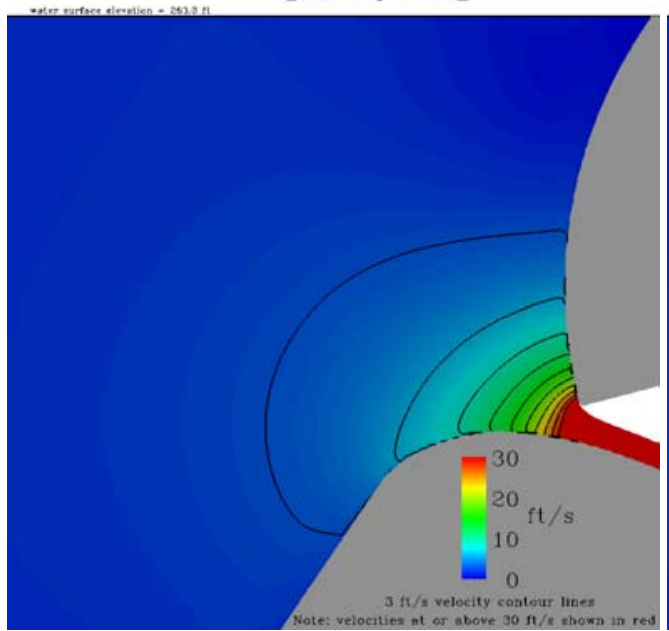

$7 \mathrm{ft}$ gate opening

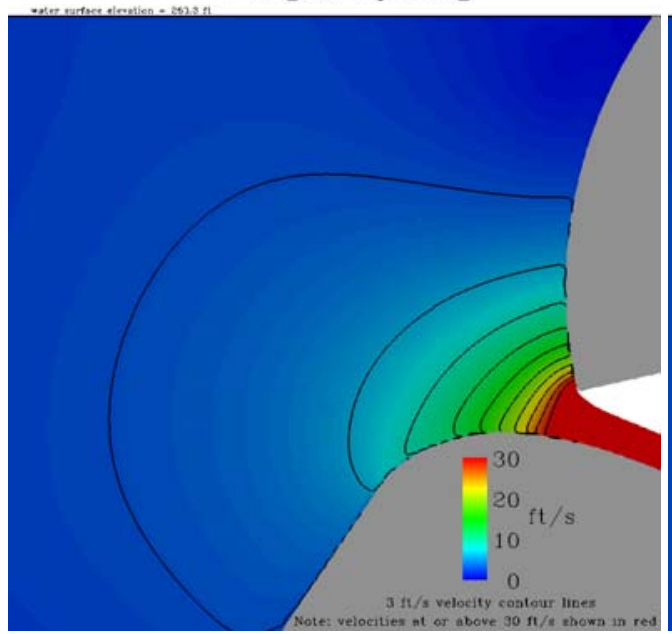

$9 \mathrm{ft}$ gate opening

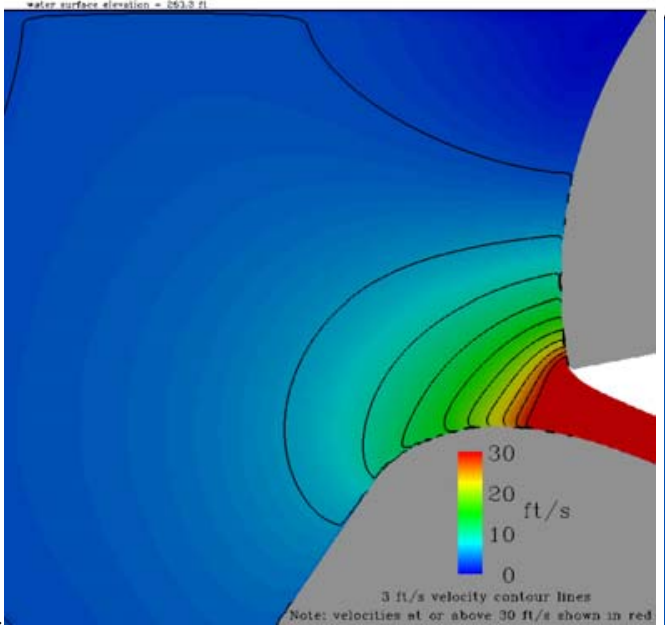

$6 \mathrm{ft}$ gate opening

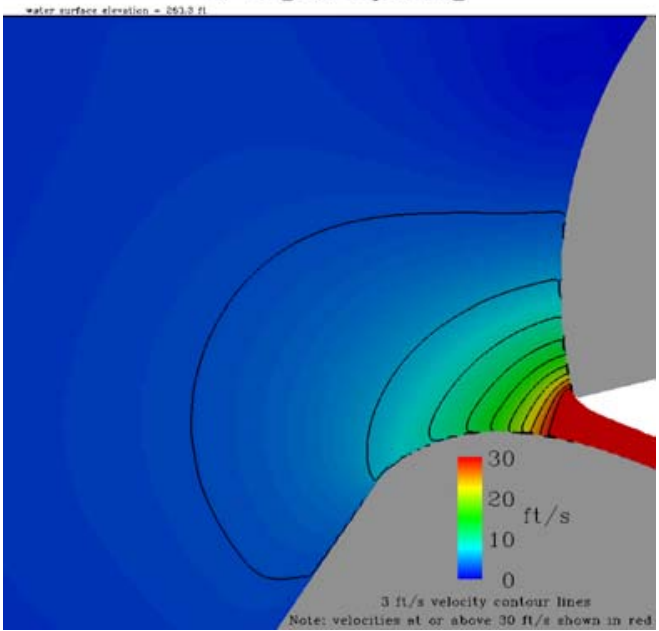

$8 \mathrm{ft}$ gate opening

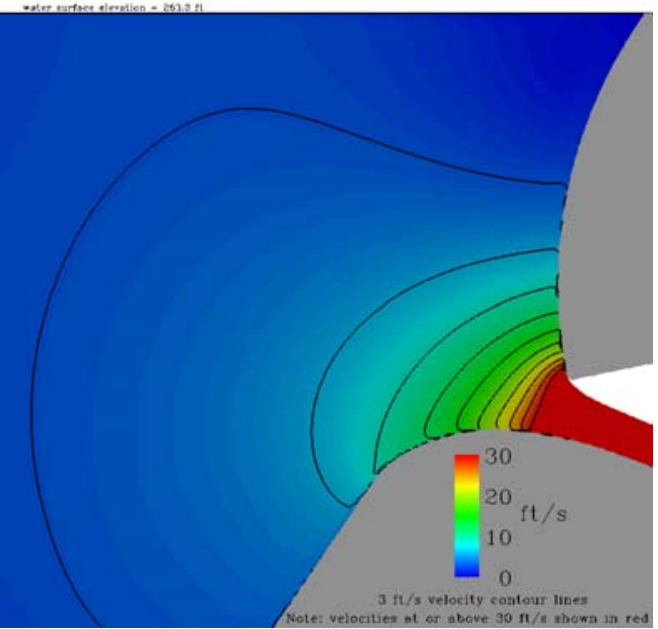

$10 \mathrm{ft}$ gate opening

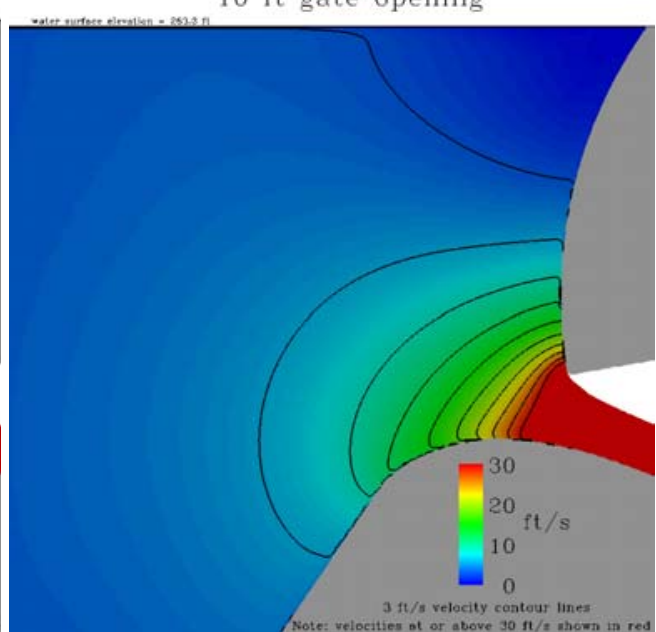

Figure 4.3. CFD Model Calculated Water Velocity Magnitude Contours of a Single Spillway Bay. Gate openings range from 1 to $10 \mathrm{ft}$. 


\subsection{Results of the CFD Analysis}

To check the sensitivity of CFD model results to the turbulence model, numerical results were resimulated using additional standard turbulence closures such as RNG, Smagorinsky-LES, and inviscid (i.e., without turbulence). Results of these sensitivity tests were almost identical to the RNG method used to generate the results in the previous section. CFD model results were also checked for sensitivity to grid resolution by splitting each computational cell into four cells. CFD simulation results from these grid sensitivity tests were virtually identical to the previous results.

CFD model results were compared to velocity vectors measured in a 1:25 scale physical model (NHC 1999). Data from the physical model compared favorably with those computed by the CFD model. Both magnitudes and directions were similar at all locations upstream of the tainter gate, and a linear regression of the velocity magnitudes produced an $\mathrm{R}^{2}$ of 0.98 .

The validated CFD model was used to generate water velocity fields upstream of the tainter gates. Velocity fields were computed for gate openings between one and ten feet in one-foot increments. Graphical simulation results are shown in Figure 4.3. In addition, numerical results throughout the domain have been preserved so that future queries of the velocity field can be made in support of potential hydroacoustic studies. 


\subsection{Recommendations}

Below are recommendations based on our evolution of transducer deployments at John Day Dam.

\subsection{Sampling Spill Bays}

1. Mount transducers at the bottom of a 21-ft-long, 3.5 -inch diameter pipe.

2. Aim $10^{\circ}$ single-beam transducers $2^{\circ}$ downstream of vertical.

3. Aim $10^{\circ}$ split-beam transducers $2^{\circ}$ downstream of vertical.

4. Deploy the pipe and transducer in the stop-log slot and attach the upper end of the pipe to the downstream wall of the slot, making certain that the pipe is oriented so that the transducer aims downstream of vertical.

5. Route cables part way up the pipe and then under the roadway up to the upstream side of the spillway deck.

6. Slow multiplex spillway transducers with a pulse repetition rate of $25 \mathrm{pings} / \mathrm{s}$ and faster if volume reverberation permits.

7. Limit the sample volume for counting fish to the deep high-discharge volume adjacent to the gate by not counting fish at ranges with flows less than about $6 \mathrm{ft} / \mathrm{s}$ at any gate opening. Use CFD model results to identify ranges from transducers where velocities will exceed $6 \mathrm{ft} / \mathrm{s}$. The proposed minimum transducer ranges for counting fish are $38 \mathrm{ft}$ for gates opened $\geq 3 \mathrm{ft}, 43 \mathrm{ft}$ for gates opened $2 \mathrm{ft}$, and $46 \mathrm{ft}$ for gates opened $1 \mathrm{ft}$, but the exact minimum range can be fine-tuned as data are collected without risk to the study because range filters are applied in post-processing after all data have been acquired.

\subsection{Sampling Intakes with STS}

1. If needed, deploy new PVC pipe for routing transducer cables through drain holes of trash-rack shelves (Figure 3.15). Previously deployed pipe should be inspected to assure that it has not worn through where it rubs against the trash-rack shelves. Also, check to see if the pipe clamps located at the bottom and top of each pipe are present and in working condition. We have no experience with how long the pipe or clamp might last.

2. Attach transducers to mounts so that they will be aimed about $36^{\circ}$ downstream off the plane of the trash rack when deployed for sampling upstream of the STS and $63^{\circ}$ downstream off the plane of the trash rack to sample downstream of the STS. The aiming process involves placing the base plate of a mount on a flat horizontal surface, aiming the transducer $36^{\circ}$ downstream of vertical if the transducer will sample upstream of a STS or aiming the transducer $63^{\circ}$ downstream of vertical if it will sample downstream of a STS. The flat horizontal surface will mimic the 
horizontal shelf in the trashrack. The transducer cable should be attached to the transducer and the topside end of the cable should be sealed against water intrusion, if necessary. A thin but stout nylon line with an end weight should be dropped through the PVC pipe to a depth of about $135 \mathrm{ft}$.

3. Divers should deploy transducers and mounts from the forebay through the vertical bars of the deepest trash rack. The transducer, mount, and bundle of transducer cable are all lowered to elevation $129 \mathrm{ft}$ on the upstream side of the trash racks. Divers should locate a drain hole in the vertical middle horizontal shelf, sweep the upper mounting area free of debris, and bolt the mount onto the top of the horizontal shelf. A bolt extending from the bottom of the mount through the drain hole is secured to the shelf by placing a flat plate and nut on the bolt from underneath the horizontal shelf.

4. The topside end of the transducer cable is attached to the nylon line previously dropped down through the PVC pipe, and crews on the forebay deck should pull the line and transducer cable up through the pipe to the surface.

5. The pulse repetition rate of transducers should be at least 25 pings/s if they are sampled in a slow multiplex or at least $15 \mathrm{pings} / \mathrm{s}$ if they are fast multiplexed.

6. After sampling in 2002, a special effort should be made to compare estimates of numbers of unguided fish from the acoustic beams sampling upstream and downstream of the STS to determine whether the downstream beam is truly necessary. Sampling with one beam and partitioning guided and unguided fish by range has distinct advantages over using two beams. The primary advantage would be that single upstream transducer could be sampled at a high ping rate for a greater portion of an hour than when two transducers are sampled. A high ping rate would improve detectability and simultaneous sampling of guided and unguided fish would reduce the variance of FGE estimates by including a covariance term in the calculations. The number of transducers required to sample one intake could either be cut in half or the spatial sampling coverage at each intake could be doubled. However, if the estimate of unguided fish were significantly higher in the downstream beam than in the upstream beam, the downstream beam should be retained for sampling unguided fish. 


\subsection{References}

NHC. 1999. John Day Dam Submerged Sluiceway: Hydraulic Model Study, Northwest Hydraulic Consultants report to US Army Corps of Engineers-Portland District, Portland, Oregon.

Ploskey, G.R. and T.J. Carlson. 1999. "Comparison of Hydroacoustic and Net Estimates of Fish Guidance Efficiency of an Extended Submersible Bar Screen at John Day Dam." North American Journal of Fisheries Management 19:1066-1079.

Poe, T., S. Anglea, and A. Giorgi. 2001. "Synthesis of Radio Telemetry, Hydroacoustic, and Survival Studies of Juvenile Salmon at John Day Dam (1980-2000)." Report to the U.S. Army Engineer District by Battelle, Inc., Richland, Washington. 
Optimization of Hydroacoustic Deployments at John Day Dam 